\title{
Adjuvant Therapies in Diabetic Retinopathy as an Early Approach to Delay Its Progression: The Importance of Oxidative Stress and Inflammation
}

\author{
Ricardo Raúl Robles-Rivera, ${ }^{1}$ José Alberto Castellanos-González, ${ }^{1,2}$ \\ Cecilia Olvera-Montaño, ${ }^{1}$ Raúl Alonso Flores-Martin, ${ }^{3}$ Ana Karen López-Contreras, ${ }^{1}$ \\ Diana Esperanza Arevalo-Simental, ${ }^{1,4}$ Ernesto Germán Cardona-Muñoz $\mathbb{D}^{1}{ }^{1}$ \\ Luis Miguel Roman-Pintos, ${ }^{5}$ and Adolfo Daniel Rodríguez-Carrizalez $\mathbb{D}^{1}$ \\ ${ }^{1}$ Institute of Clinical and Experimental Therapeutics, Department of Physiology, Health Sciences University Center, \\ University of Guadalajara, Guadalajara, Jalisco, Mexico \\ ${ }^{2}$ Department of Ophthalmology, Specialties Hospital of the National Occidental Medical Center, Mexican Institute of Social Security, \\ Guadalajara, Jalisco, Mexico \\ ${ }^{3}$ Department of Ophthalmology, Regional General Hospital 110, Mexican Institute of Social Security, Guadalajara, Jalisco, Mexico \\ ${ }^{4}$ Department of Ophthalmology, Hospital Civil de Guadalajara "Fray Antonio Alcalde", Guadalajara, Jalisco, Mexico \\ ${ }^{5}$ Department of Physiology, University Center of Tonala, University of Guadalajara, Tonala, Jalisco, Mexico
}

Correspondence should be addressed to Adolfo Daniel Rodríguez-Carrizalez; adolfo.rodriguez@academicos.udg.mx

Received 30 October 2019; Revised 16 January 2020; Accepted 8 February 2020; Published 11 March 2020

Guest Editor: Ayman M. Mahmoud

Copyright (c) 2020 Ricardo Raúl Robles-Rivera et al. This is an open access article distributed under the Creative Commons Attribution License, which permits unrestricted use, distribution, and reproduction in any medium, provided the original work is properly cited.

\begin{abstract}
Diabetes mellitus (DM) is a progressive disease induced by a sustained state of chronic hyperglycemia that can lead to several complications targeting highly metabolic cells. Diabetic retinopathy (DR) is a multifactorial microvascular complication of DM, with high prevalence, which can ultimately lead to visual impairment. The genesis of DR involves a complex variety of pathways such as oxidative stress, inflammation, apoptosis, neurodegeneration, angiogenesis, lipid peroxidation, and endoplasmic reticulum (ER) stress, each possessing potential therapeutic biomarkers. A specific treatment has yet to be developed for early stages of DR since no management is given other than glycemic control until the proliferative stage develops, offering a poor visual prognosis to the patient. In this narrative review article, we evaluate different dietary regimens, such as the Mediterranean diet, Dietary Pattern to Stop Hypertension (DASH) and their functional foods, and low-calorie diets (LCDs). Nutraceuticals have also been assessed in DR on account of their antioxidant, anti-inflammatory, and antiangiogenic properties, which may have an important impact on the physiopathology of DR. These nutraceuticals have shown to lower reactive oxygen species (ROS), important inflammatory factors, cytokines, and endothelial damage biomarkers either as monotherapies or combined therapies or concomitantly with established diabetes management or nonconventional adjuvant drugs like topical nonsteroidal anti-inflammatory drugs (NSAIDs).
\end{abstract}

\section{Introduction}

Diabetic retinopathy (DR) is the number one cause of blindness in people between 26 and 75 years of age, and it is estimated that 191 million people will be diagnosed with DR by 2030 [1]. DR is an often-overlooked complication of diabetes mellitus (DM); however, diabetes-related blindness may cost up to $\$ 500$ million annually in the US. This may be because of the limited therapeutic options that exist to lessen its progression in early stages [2], which emphasizes even more the importance of an early, effective approach that would offer a much better prognosis to the patient. Other nonconventional therapies have been reviewed widely as novel treatment; however, none has shown any clinical 
significance to change the expectant approach from specialized ophthalmologists [3]. Until now, ophthalmologists prefer to optimize glycemic control and other comorbidities with a one-year recall until there is evidence of proliferative diabetic retinopathy (PDR).

In this narrative review, we aim to approach different diets and their effects on DR and different nutraceuticals that have shown antioxidant and anti-inflammatory properties proven to have different outcomes in the genesis and development of DR. To achieve this, we searched the published literature through online databases such as Embase, PubMed, Scopus, Web of Science, Google Scholar, and Science Direct, using the following search terms: "diabetic retinopathy," "adjuvant therapy," "inflammatory," "inflammation," "oxidative stress," "antioxidant therapy," "diet," "dietary," "supplementation," "nutraceuticals," "combined therapy," "dash," "Mediterranean," "low-calorie," "NSAID," "bromfenac," "nepafenac," "topical," "fenofibrates," "brimonidine," "captopril," and "angiotensin receptor"; we included English language articles that showed relevance either in clinical or in preclinical stages in DR, with the oldest article being from 1992 up to November 2019. We took into consideration articles that contribute to the discussion of adjuvant therapies to stabilize or to delay the progression of DR. We are considering an adjuvant therapy as a nontraditional or nonstandardized "add on" treatment [4] that acts in the physiopathological mechanisms of DR, taking into consideration that these do not replace the established DM management.

\section{Physiopathology}

$\mathrm{DR}$ is a complex disease that comes from the alteration of various pathways affecting the retina. The retina is susceptible to damage from high-glucose concentrations by being a highly metabolically active tissue, especially after 6 years of diagnosis [5]. Chronic hyperglycemia is the main risk factor involving DR, and it has been shown to induce vascular endothelial dysfunction in the retina [6] by damaging pericytes. If injury by high glucose persists, other pathways besides glycolysis (such as polyol, hexosamine, and advanced glycation) will be activated, the latter known to induce apoptosis and degeneration of pericytes, and thus, the retina will be damaged over time [7]. These changes can be clinically observed with ophthalmoscope-like microaneurysms, intraretinal microvascular abnormalities, and neovascularization leading to formation of exudates and hemorrhages [8].

According to previous research, independent metabolic pathways are connected between hyperglycemia and DR [9] (see Figure 1). Oxidative stress (OS) is associated with inflammation [10]; mitochondrial dysfunction, apoptosis, and DNA repair system dysfunction [11]; and neurodegeneration due to the formation and augmented concentration of reactive oxygen species (ROS) [1], with the latter inducing inflammation and mitochondrial dysfunction ultimately leading to cell death [12]. OS has been one of the most studied therapeutic approaches besides endothelial dysfunction.

Another important and widely studied pathway involved in DR is inflammation, where many cytokines: interleukin$1 \beta$ (IL-1 $\beta$ ), interleukin-6 (IL-6), interleukin-8 (IL-8), tumor

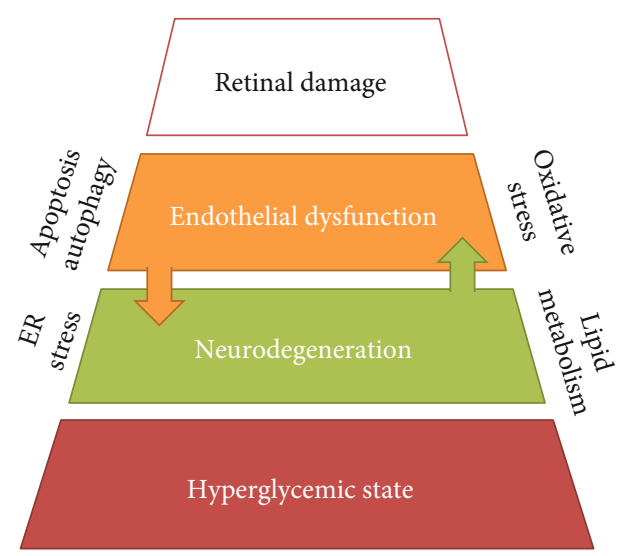

FIGURE 1: Diabetic retinopathy physiopathology pyramid. This is a representation of DR's pathophysiology on how every step leads to the next upper one. Hyperglycemic state is the first step, followed by neurodegeneration and endothelial dysfunction, underlying oxidative stress, endoplasmic reticulum (ER) stress, lipid metabolism abnormalities, apoptosis, and autophagy as a complex interconnected pathophysiology leading to retinal damage in DR.

necrosis factor- $\alpha$ (TNF- $\alpha$ ), and monocyte chemoattractant protein-11 (MCP-11) as seen in Figure 2, have been reported in ocular tissues in preclinical and clinical studies. Inflammation correlates with an increased concentration in PDR over early stages [13]. Lipid metabolism is a biomechanism that plays an important role in the genesis of DR; for example, large omega-3 polyunsaturated fatty acids (PUFAs) play a regulating role on vascular function and angiogenesis as shown by Eid and colleagues [14]. Other mechanisms are also described, such as endoplasmic reticulum (ER) stress where the proteostasis mediated by chronic conditions such as DM activates signaling pathways as protein kinase R/PKR-like ER kinase from unfolded protein response, and autophagy is overwhelmed, leading to cell death [15].

\section{Dietotherapy in Diabetic Retinopathy}

Nutrition plays an important role in controlling the diabetes progression and its complications [16]. Optimizing glycemic and lipid control is one of the first-line interventions in diabetes, which also reduces the progression of DR [17]. However, here, we will focus on antioxidant-rich specific diets and supplements as an adjuvant therapy to the usual diabetes management.

Specific recommendations on diet, its components, or different nutraceuticals exerting their effects on type II diabetes mellitus (T2DM) have been reviewed. As an example, there are very low-calorie diets (VLCD) [18-20], which have shown to be effective on weight and glycemic control on patients with T2DM.

Other components of an everyday diet worth mentioning that have already been discussed regarding DR are PUFAs, which are associated with reduced prevalence and progression of DR [21]. A moderate consumption of alcohol [22], especially white and fortified wines [23], has also been studied with inconclusive results on the effects in DR according 


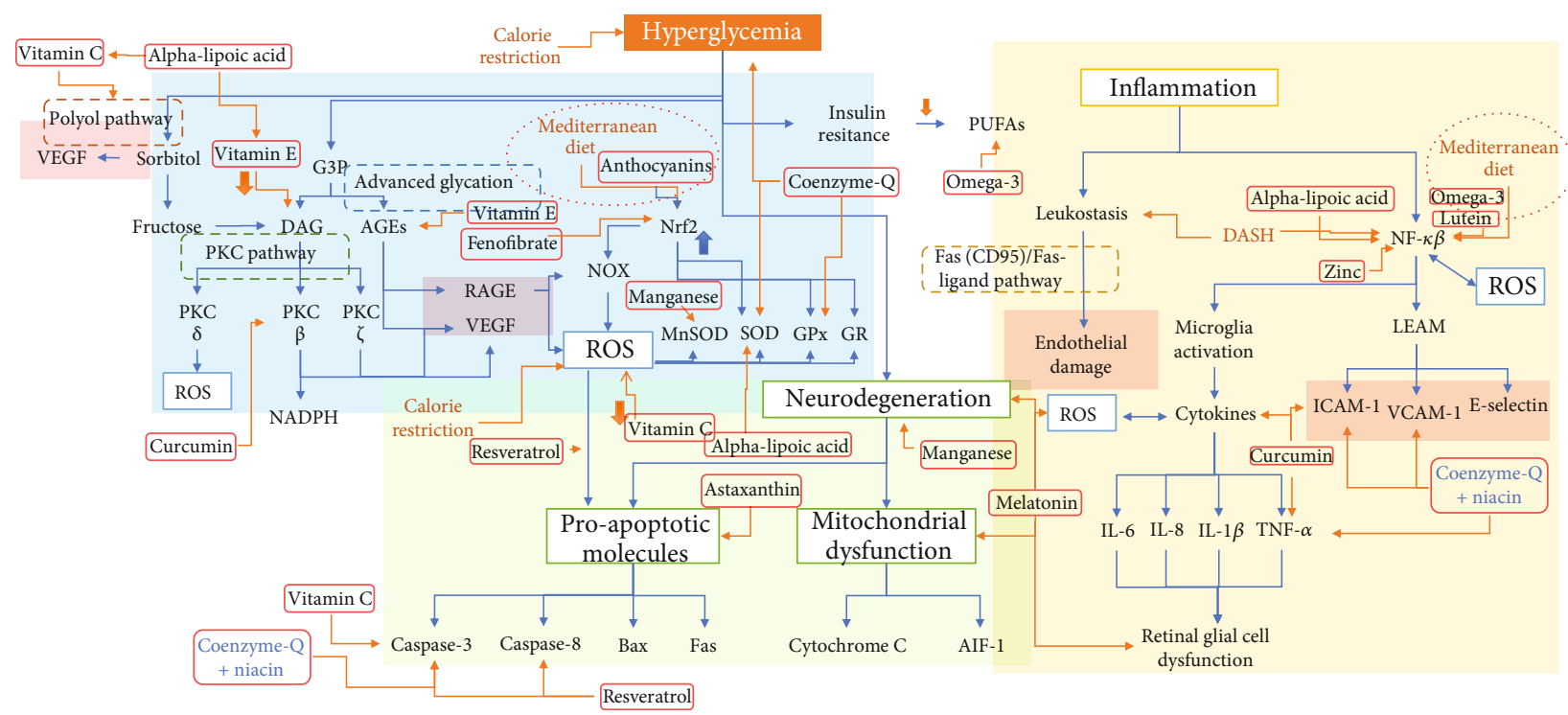

FIGURE 2: DR's physiopathology and biomarkers for each intervention. Hyperglycemia induces a variety of biochemical responses derived in angiogenesis (as shown by VEGF and endothelial damage), apoptosis, and retinal dysfunction; here, we describe where each intervention acts in these complex pathways by inhibiting the shown biomarker. Abbreviations: VEGF: vascular endothelial growth factor; G3P: glyceraldehyde 3-phosphate; DAG: diacylglycerol; AGEs: advanced glycation end products; RAGE: receptor for advanced glycation end products; PKC: protein kinase C; NOX: NADPH (nicotinamide adenine dinucleotide phosphate) oxidase; ROS: reactive oxygen species; SOD: superoxide dismutase; MnSOD: manganese superoxide dismutase; GPx: glutathione peroxidase; GR: glutathione reductase; ICAM-1: intercellular adhesion molecule-1; VCAM-1: vascular cell adhesion molecule-1; MCP-1: monocyte chemoattractant protein-1; TNF- $\alpha$ : tumor necrosis factor-alpha; IL-6: interleukin-6; IL-8: interleukin-8; IL-1 $\beta$ : interleukin-1 $\beta$; PUFAs: polyunsaturated fatty acids; AIF-1: apoptosis-inducing factor-1; Bax: Bcl-2-associated X protein; LEAM: leukocyte-endothelium adhesion molecules; DASH: Dietary Pattern to Stop Hypertension.

to different cohorts [24, 25]; and progressive studies [26] show no association between their consumption and the onset or progression of DR. Furthermore, high sodium intake, an important aspect of the Dietary Pattern to Stop Hypertension (DASH) diet, may be related with progression of DR, showing correlation in patients with type I diabetes mellitus (T1DM) [27], but not showing an association in other progressive studies [28] nor in patients with T2DM [29]. Carbohydrate intake independently has proven not to be associated with DR [30], which brings attention to the importance of understanding the pathophysiological mechanisms involved in the genesis and progression of DR, suggesting that its treatment requires a different approach other than diabetes management alone.

Mediterranean diet is a recognized overall healthy diet, and it has been shown to have a protective effect against DR $[31,32]$. It contains a high amount of fish and extra virgin olive oil rich in omega-3 PUFAs [33] and mixed nuts rich on polyphenols that may reduce the risk of developing diabetes [34] and benefits insulin resistance [35] (see Table 1). This diet is rich in anti-inflammatory and antiangiogenic factors such as the nuclear factor erythroid 2-related factor 2 (Nrf2) which also increases antioxidant enzyme activity [36] (as seen in Figure 2). Augmented intake of vitaminrich food as fruits and vegetables, as well as supplements, has been related to a risk reduction of chronic diseases [37] and DR itself [38]. This high fruit and vegetable consumption has shown hypoglycemic effects due to their bioactive compounds such as flavonoids, alkaloids, and anthocyanins being present in wild blueberry, bilberry, cranberry, elderberry, raspberry seeds, and strawberry which have shown to have powerful antioxidant activity [39]. Other micronutrients such as vitamins $\mathrm{C}$ and $\mathrm{E}$ have not shown an association between DR risk and intake of these vitamins [40] in contrast to a prospective study on fruit consumption and DM and its vascular complications [41]. Mediterranean diet through its dietary components acts in dyslipidemia, inflammation, oxidative stress, and hyperglycemia through some of the nutraceuticals discussed in this article which we focus as potential monotherapy or combined therapy agents [42].

Coffee and caffeine have been studied in DR, and conclusiveness has not yet been achieved. A cohort study conducted by Lee et al. in 2016 concludes that drinking coffee without milk or sugar at least three times daily has a preventive effect on diabetes [43]. Such influence is associated with chlorogenic acid on the lipid and glucose metabolism. However, coffee intake showed neither association to a lower risk of progression nor in development of DR in clinical studies [44] whereas in preclinical studies showed a protective role inhibiting apoptosis induced by hyperglycemia in retinal tissues [45].

Nutrients in diet can play a massive role in diabetic patients who are resistant to conventional treatment, as these nutritional strategies can reduce the risk of developing DR and attenuate its progression, preserving the normal function and structure of the retina [46]. All these compounds or nutraceuticals have a specific beneficial effect, and when talking about DR, we aim for nutraceuticals that exert their effect on any pathway in the physiopathology of DR [47] as adjuvant therapies. 


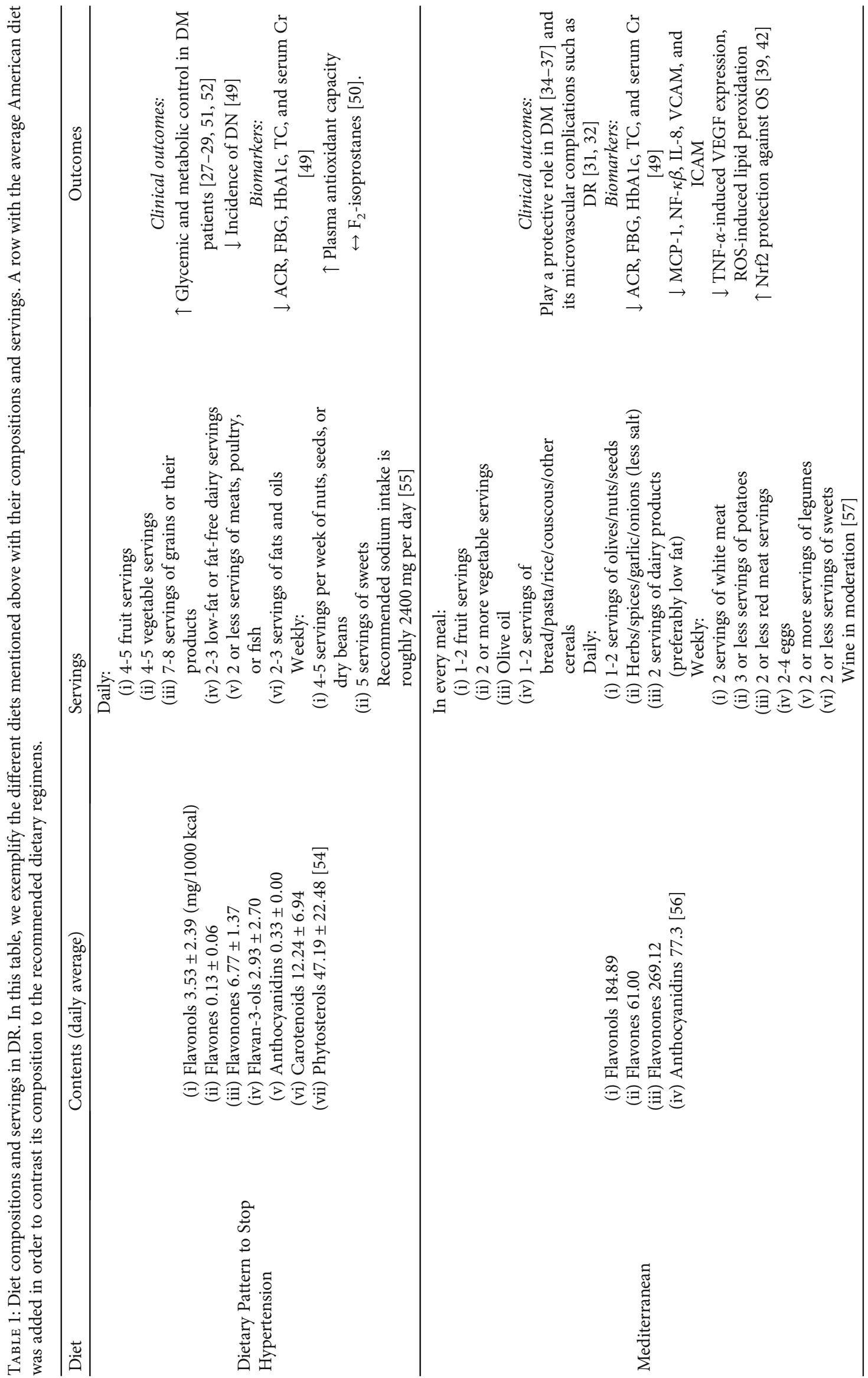




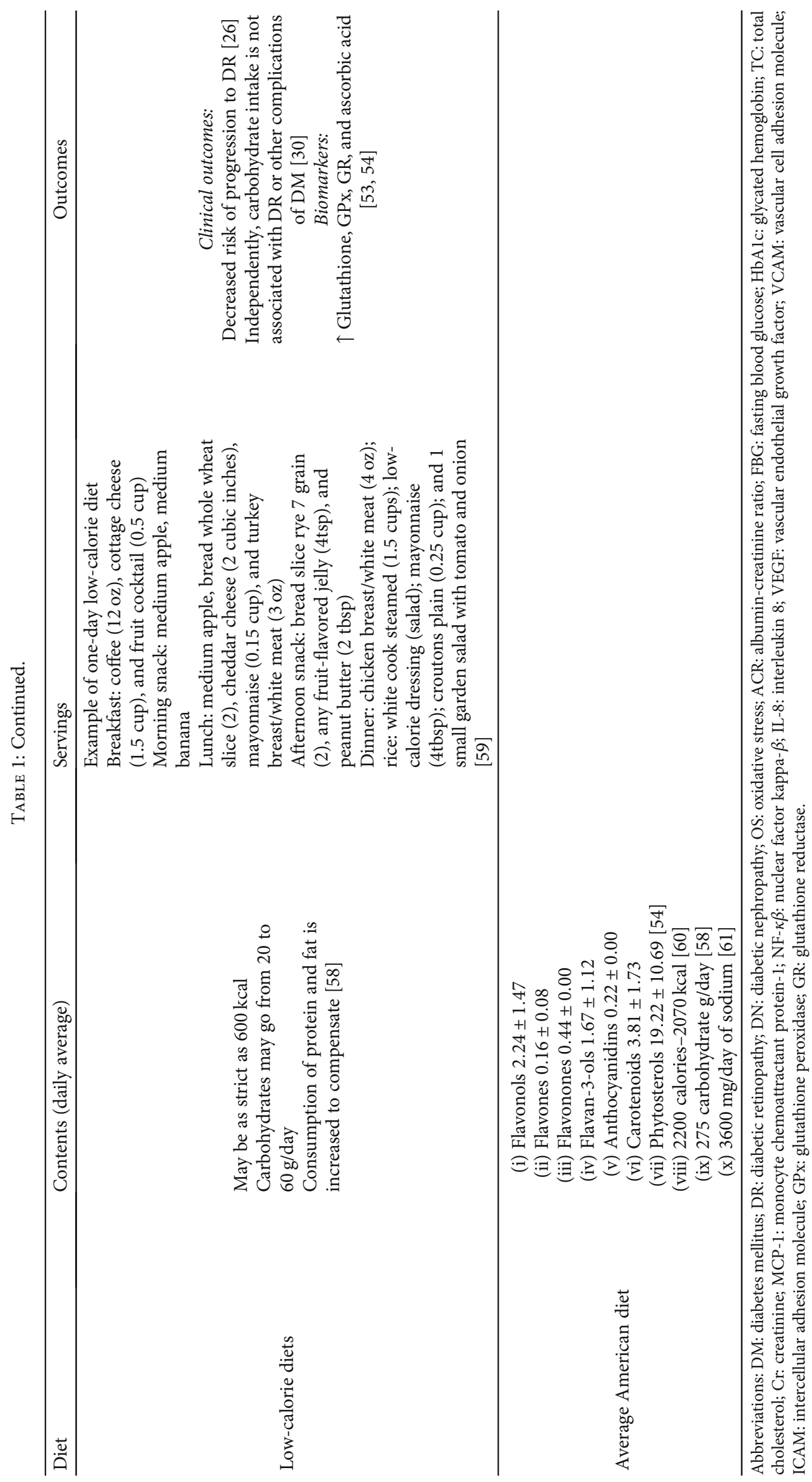


The DASH diet is based on respecting the following dietary recommendations: limiting sugar-sweetened beverages and sweets; limiting foods that are high in saturated fats, full-dairy products, or tropical oils; consuming vegetables, fruits, whole grains, fat-free or low-fat dairy products, fish, poultry, beans, nuts, and vegetable oils; and thus a greater intake of phytochemicals (see Table 1) [48]. Although this is a dietary pattern related to nutritional management of hypertension, it has shown some beneficial effects on some complications of diabetes. In elderly Korean population, the DASH diet decreases the odds of chronic kidney disease and leads to a lower overall likelihood of diabetic nephropathy (DN), associated with the anti-inflammatory and antioxidant properties of the diet [49] (see Figure 2). In another study, regarding obese population, the DASH diet improved serum antioxidant capacity measured by a higher ferric reducing/antioxidant power of plasma [50]. The DASH diet is a potential strategy for reduction of T2DM and for metabolic control of the disease by improving glycemic and cholesterol control $[51,52]$. To our knowledge, there are no studies on the effects of the DASH diet in DR.

The aforementioned diets contain overall healthy food which are rich in some of the specific nutraceuticals we will discuss later. Nonetheless, there is another approach worth mentioning regarding diet and its impact on DR. The lowcalorie diet (LCD) is another alternative that has been studied in pro of T2DM (see Table 1). Cohort studies have positively correlated high calorie intake with progression of DR [26]. Calorie restriction slows down age-related deterioration of ocular functions by attenuating mainly OS and improving mitochondrial function [53]. In preclinical studies, a lowcarbohydrate diet improved antioxidant biomarkers [54].

The VLCD has been assessed on T2DM patients, with contradictory findings. Reported cases have found this intervention beneficial in glycemic control, but there are no specific trials assessing VLCDs in DR $[62,63]$. Nevertheless, caution is needed since VLCDs lower than $600 \mathrm{kcal}$ should only be employed under close clinical supervision [27], and rapid reduction of systemic glucose is associated with worsening of DR [64].

\section{Supplement Therapies and Diabetic Retinopathy}

A wide variety of nutraceuticals, phytochemicals, vitamins, and minerals with antioxidant and/or anti-inflammatory properties, have been shown to play a major role on the onset and progression of DR. Some have been studied as single therapies and others as combined therapies probably because of each one on different points of some, or most, of the routes involved in DR (see Figure 2). Among the pool of options, we considered molecules that have been consistently associated with eye health and/or DR; we also include some relatively new dietary supplements which have shown positive results as promising adjuvant therapies in DR.

4.1. Xanthophylls. Xanthophylls are carotenoids that contain oxygen; they are derived from plants as natural pigments and are widely known for their antioxidant properties. Two of the major xanthophylls, containing two hydroxyl groups in their structure and having no effect as provitamin A, are lutein and zeaxanthin. Both substances are found in the fovea; lutein concentration is superior to zeaxanthin which differs from lutein in its double link in one of its hydroxyl groups [1]. These xanthophylls exert a wide variety of effects involved in the genesis of DR. As antioxidants, they act by alternating their single and double links reducing blue light wavelength and protecting the eye from light-induced OS, and in this way, around $90 \%$ of blue light is absorbed [65]. Xanthophylls act on glucose and lipid metabolism by the upregulation of peroxisome proliferator-activated receptors (PPARs) and glucose transporters and its effects in the expression of enzymes involved in fatty acid synthesis and cholesterol metabolism [66].

Lutein acts on inflammation by quenching free radicals leading to the blockade of nuclear factor kappa- $\beta$ (NF- $\kappa \beta)$ pathway activation and by the inhibition of arachidonic acid release, and, in consequence, keeping prostaglandins, thromboxanes, and leukotrienes from being formed [67]. Lutein also can inhibit IL-8 secretion [68] and phosphoinositide 3-kinase (PI3K) activity when it is secondarily increased due to OS [69]. Zeaxanthin was related to restoring vascular endothelial growth factor (VEGF) concentrations in a preclinical study alongside restoring as intercellular adhesion molecule-1 (ICAM-1) comparable to the control group [70].

Astaxanthin is a ketone carotenoid that can bind both from the inside and outside of the cell membrane, a quality that makes it the strongest antioxidant of this family [71]. It can be found in seafood and microalgae (Haematococcus pluvialis) [72]. Astaxanthin has proven to be efficient against OS as an antioxidant, in addition to having anti-inflammatory and antiapoptotic properties, underlining its importance in neurodegeneration in DR [73]. In preclinical studies, this xanthophyll has shown to decrease OS damage-induced biomarkers and to increase glutamine synthetase concentrations in Müller cells, reducing apoptosis in retinal ganglion cells as seen in Figure $2[74,75]$. Astaxanthin can also regulate glycemic states and reduce insulin resistance and exert an antiinflammatory effect by decreasing the expression of NF- $\kappa \beta$ and TNF- $\alpha$ [76] and by inhibiting the expression of proinflammatory molecules such as ICAM-1 and monocyte chemoattractant protein-1 (MCP-1) and angiogenesis via VEGF [66].

Xanthophylls and other carotenoids have proven to be useful in DR's pathological mechanisms, and they have even shown the ability to diminish OS in retinal tissues when conditioned to chronic hyperglycemic state [68-71, 76-78].

4.2. Vitamin C. A water-soluble vitamin that can be found in many natural sources that have been used as capsules and powder in many formulations as a supplement, vitamin $\mathrm{C}$ exists in two main forms, ascorbic and dehydroascorbic acid, and it is an important nutraceutical in the aid of many OS-oriented diseases [1]. Ascorbic acid has even been studied in clinical trials regarding obesity in DM alongside pomegranate leaf extract like a bioactive compound [79] and in the improvement of the lipid profile [80]. The main biological functions of ascorbic acid revolve between its 
TABLE 2: Relationship between nutraceuticals and the pathophysiological pathways of DR. The " $\checkmark$ " on each cell indicates whether the nutraceutical (rows) has shown an effect on each mechanism (columns). In this table, it is remarkable how every nutraceutical has at least some antioxidant effect. Since various mechanisms are involved in DR, we can then aim the therapeutic approach to several targets. ${ }^{*}$ High doses may be prooxidant instead of antioxidant.

\begin{tabular}{|c|c|c|c|c|c|c|}
\hline \multicolumn{7}{|c|}{ Diabetic retinopathy } \\
\hline Nutraceutical & Oxidative stress & Inflammation & Angiogenesis & $\begin{array}{l}\text { Apoptosis and } \\
\text { autophagy }\end{array}$ & $\begin{array}{l}\text { Antidiabetes } \\
\text { properties }\end{array}$ & $\begin{array}{c}\text { Endoplasmic reticulum } \\
\text { stress }\end{array}$ \\
\hline Xanthophylls & $\checkmark$ & $\checkmark$ & $\checkmark$ & & & \\
\hline Vitamin C & $\checkmark$ & & $\checkmark$ & $\checkmark$ & & \\
\hline Vitamin E & $\checkmark$ & & $\checkmark$ & & $\checkmark$ & \\
\hline Zinc & $\checkmark$ & $\checkmark$ & & & & \\
\hline Alpha-lipoic acid & $\checkmark$ & $\checkmark$ & $\checkmark$ & $\checkmark$ & & \\
\hline Manganese & $\checkmark^{*}$ & & & & $\checkmark$ & \\
\hline Curcumin & $\checkmark$ & $\checkmark$ & $\checkmark$ & & $\checkmark$ & \\
\hline Polyphenols and resveratrol & $\checkmark$ & $\checkmark$ & $\checkmark$ & $\checkmark$ & $\checkmark$ & \\
\hline Ubiquinone & $\checkmark$ & & & $\checkmark$ & $\checkmark$ & \\
\hline Erianin & $\checkmark$ & $\checkmark$ & $\checkmark$ & & & \\
\hline Omega-3 fatty acids & $\checkmark$ & $\checkmark$ & $\checkmark$ & & & $\checkmark$ \\
\hline Melatonin & $\checkmark$ & $\checkmark$ & $\checkmark$ & $\checkmark$ & & $\checkmark$ \\
\hline
\end{tabular}

ability to act in redox state and as a cofactor for many human enzymes [81, 82]. Ascorbic acid has been found to be in higher concentration in healthy patients, contrary to those with DR who have lower concentrations than patients with DM who have not developed this complication [83] and especially in those who develop diabetic macular ischemia who showed dramatically decreased concentrations compared to nondiabetic controls [84]. This effect is due to its ability to prevent propagation of free radical-induced chain reactions [85], thereby directly scavenging ROS (see Figure 2), preventing breakdown of nitric oxide (NO) and decreasing low-density lipid oxidation $[46,86,87]$. Ascorbic acid also plays a role in angiogenesis (Table 2) by inhibition of VEGF, protecting the endothelial barrier permeability [88].

Ascorbic acid has already been discussed as an adjuvant therapy in many inflammation-mediated disorders because of its anti-inflammatory, immunostimulant, and even antibacterial properties at different doses alongside other medications [89-91], extending its important role to be used as combined therapy rather than monotherapy. Nevertheless, further investigations are needed to assess its efficacy in DR as an adjuvant therapy. Regarding OS, in a clinical study with $1000 \mathrm{mg} /$ day of ascorbic acid, it reduces the activity of the enzyme aldose reductase and thus acts by inhibiting the polyol pathway [92] as shown in Figure 2. Ascorbic acid also prevents the apoptosis of vascular pericytes [93]. It may also have a role in autophagy and apoptosis by induction of autophagosome formation [94], increasing the rate of protein degradation lysosomes [95] and expression Bcl-2 family proteins between hypoxia and reoxygenation status [96].

4.3. Vitamin E. Vitamin E is the most important lipid-soluble chain-breaking antioxidant in tissue, red cells, and plasma. The predominant isomer found in the human body is $\alpha$-tocopherol $[1,97]$. Lipid metabolism is one of this vitamin's main targets, specifically lipid peroxidation. Vitamin E inhibits malondialdehyde (MDA) formation [98, 99] inducing singlet oxygen, lipid peroxide products, and superoxide radical to form tocopherol radical [100].

Vitamin E can inhibit AGE formation in vitro[98], probably due to the protective role that vitamin E exerts on lysosomes to reduce autophagic stress [101]; however, this has only been studied in DN to our knowledge and has yet to show the same properties in retinal tissues.

The dietary intake of vitamin $\mathrm{E}$ was associated by Arablou and colleagues with higher catalase enzyme activity [102]. Independently to its antioxidant properties, the $\alpha$-tocopherol, although dose-dependent ranging from 10 to $50 \mu \mathrm{M}$, has been shown to be able to inhibit protein kinase $\mathrm{C}$ activity [103]. In preclinical studies, $\alpha$-tocopherol increased glutathione reductase (GR) activity, reduced glutathione peroxidase (GPx), and ameliorated total antioxidant capacity [95] and inflammatory response measured with the inflammatory cytokines IL-1 $\beta$, IL-6, and TNF- $\alpha$ [104]. Vitamin E can decrease the total diacylglycerol level and thus prevent the abnormal retinal flow like expressed in Figure 2 [105]. Tocotrienol, in vivo, also acts as an antiangiogenic agent by decreasing apoptosis of endothelial cells via the growth factor-dependent phosphatidylinositol 3-kinase/PDK/Akt signaling pathway [106]. Even though vitamin E as monotherapy has not proven efficacy on DR in clinical studies [16], in combination with other agents, it may aid DR treatment when targeting both OS and inflammation, though further investigation is still needed.

4.4. Zinc. Zinc is the second most abundant trace element in the human body, essential for the structure and function of numerous macromolecules such as lipids, nucleic acids, and enzymes that regulate homeostasis, immune responses, OS, apoptosis, and aging $[107,108]$. Zinc can be found in a wide variety of food and beverages in low quantities [109]. A low dietary zinc intake has been associated with a greater 
likelihood of subretinal fluid in patients with neovascular age-related macular degeneration [110]. Serum zinc levels are significantly lower in patients with DR and even correlate with the severity of DR [111] along with being an independent risk factor for DN [112], thus suggesting its negative effects on the microvasculature.

Zinc acts as a cofactor of the cytosolic and extracellular $\mathrm{Zn} / \mathrm{Cu}$ superoxide dismutase (SOD) enzyme, which scavenges ROS by catalyzing the dissociation of the $\mathrm{O}_{2}{ }^{-}$radical in the less harmful forms $\mathrm{O}_{2}$ and $\mathrm{H}_{2} \mathrm{O}_{2}[1,107]$. This mineral has a unique role in the phototransduction process and photoreceptor-retinal pigment epithelial interaction, and it induces the expression of metallothioneins which in the long term will function as an effective antioxidant and anti-inflammatory [108].

In preclinical studies, zinc supplementation has shown beneficent effects over OS microvascular damage by clearing free radicals, inhibiting lipid peroxidation, activating metallothionein, and reducing the expression of VEGF [112]. Zinc has a positive relationship with vitamin A levels for it is an essential element in retinol-binding protein [111] and it may also improve the absorption of vitamin $\mathrm{E}$ in food [113].

Zinc is needed for its catalytic function in over 100 specific enzymes, indicating the critical role of this element in cellular processes [114], including events of genomic stability, cognitive functions, depression, and OS [115]. Zinc by itself is not actively redox, and therefore, $\mathrm{Zn}^{2+}$ does not interact directly with ROS or with free radicals centered on carbon as seen in Figure $2[116,117]$. Zinc, then, contributes to antioxidant status through its ability to compete with transition metals and copper for binding sites in the cell membrane (Table 1) [118]. Iron and copper ions catalyze the production of lipoperoxides; therefore, their replacement by zinc under conditions of insulin resistance in the plasma membrane could inhibit lipoperoxide formation [119].

Multiple preclinical and clinical studies regarding zinc and DR have been developed with various assessed outcomes such as angiogenesis, where a 3-month therapy with zinc did not alter serum VEGF, brain-derived neurotrophic factor, and nerve growth factor in animal models [120]. In a model of induced insulin resistance in rats, zinc supplementation increased insulin sensitivity and antioxidant capacity, where the antioxidant enzymes catalase, glutathione, GPx, and SOD were diminished in comparison with control models. Zinc supplementation in these animals restored the activity of the enzyme and glutathione synthesis [114]. It also attenuates the OS induced by diabetes in the bloodstream and protects the retina from diabetes-induced increased lipid peroxidation $[118,121]$. Concerning inflammation, zinc has multiple mechanisms to ameliorate inflammatory processes such as reducing cytokine production by upregulating the zinc-finger protein A20 and inhibiting NF- $\kappa \beta$ activation, and consecutively by inhibiting NADPH oxidase, it also prevents the formation of ROS [122]. Blood glucose level is also reduced in T2DM animal models given zinc oxide nanoparticles, with the improvement of glucose metabolism and insulin resistance, in addition to the significant reduction of circulating triglycerides and free fatty acids [123]. Zinc supplementation has a potential ability to hinder diabetes- induced cataracts through downregulation of the polyol pathway [124]; however, it has yet to show a similar effect regarding retinal tissue. Some studies have shown an insufficient dietary consumption zinc, particularly among the elderly [110] that may be associated with increased DNA damage in this population [115].

4.5. Manganese. Manganese ( $\mathrm{Mn})$ is an essential element present in nature as the fifth most abundant metal in the environment and an essential micronutrient for humans [1] that may be associated with microvascular complications in DM. Mn can be found in a normal diet mostly in legumes, rice, nuts, and whole grains [125]. Only about $5 \%$ of the $\mathrm{Mn}$ in the diet seems to be absorbed [126]. Mn participates in various mechanisms involved in the genesis of DR, like the generation of ROS by having prooxidative properties and antioxidant mechanisms [127], and it could have a role in inflammation. In fact, the dietary intake of this micronutrient was inversely associated with the incidence of T2DM and was partially associated with lower OS measured by 8-hydroxydeoxyguanosine [128]; nevertheless, in preclinical studies, both deficient or excessive intake of Mn aggravated apoptosis by upregulating capase-3, caspase-8, and caspase9 and inhibited Nrf2 signaling, while optimal intake protected against ROS, MDA, and protein carbonyl [129]. Mn may have a protective role against endothelial dysfunction by upregulating disulfide bond A-like protein (DsbA-L) and thus increasing adiponectin, which ultimately downregulate ICAM-1, a biomarker of endothelial dysfunction; nonetheless, its evaluation in retinal tissues is necessary [130]. Toxicity is caused mainly because of an excessive dose, primarily from supplementation or nondietary intake; and it has been identified through behavioral abnormalities such as hyperactivity, inferior intellectual function, impaired motor skills, and reduced olfactory function in children [125] and in association with the increase of inflammatory cytokines IL- $1 \beta$, IL-6, and IL-8 and higher methylation of NF- $\kappa \beta$ member activator NKAP [131].

With regard to OS, manganese superoxide dismutase (MnSOD) is an important mitochondrial antioxidant enzyme in which Mn acts as a cofactor [127]. The Mn is an activator of gluconeogenic enzymes like pyruvate carboxylase and isocitrate dehydrogenase, which protect the mitochondrial membrane through the protective role of SOD in lipoperoxidation, emphasizing its importance in mitochondrial metabolism [132, 133]. In preclinical studies with rats on high-fat diets, $\mathrm{Mn}$ improved synthesis and secretion of insulin, which is consistent with the improved mitochondrial function [134]. Also, Mn has various beneficial effects in the aid of different biomechanisms involving different pathologies and specifically in DR, but its usage is still limited due to limited information available in such a specific tissue like the retina.

4.6. Alpha-Lipoic Acid. Alpha-lipoic acid is a natural compound found primarily in vegetables and meats (and nowadays in many supplementary components), and it is essential for mitochondrial function, showing a promising role in DR. Also known as thioctic acid, this nutraceutical 
possesses both hydrophilic and hydrophobic properties, widely distributed through cytosol and cellular membranes [135]. Alpha-lipoic acid is a potent antioxidant, improving insulin sensitivity and fatty acid oxidation by activating AMP-activated protein kinase in diabetic patients [136]. It can inhibit lipid and protein oxidation and ROS scavengers [137]. Lipoic acid induces Nrf2 binding to antioxidant response elements and thus higher gamma glutamylcysteine ligase and its catalytic subunit, and so it ameliorates antioxidative processes related with age [137]. Dihydrolipoic acid can regenerate endogenous antioxidants, such as ascorbic acid, tocopherol, and glutathione [138, 139]. Regarding angiogenesis, in preclinical studies, monotherapy with alpha-lipoic acid decreased the expression of VEGF in cardiac tissue [140], angiopoietin 2, and erythropoietin, protecting the diabetic rat's retina. This is achieved by blocking superoxide formation [141] with the protection of the thickness of ganglion cells [142] and by a probable inhibition of NF- $\kappa \beta$ (having an important role in inflammation as seen in Figure 2). Alpha-lipoic acid may inhibit endothelial cell apoptosis by activating protein kinase B and upregulating p27 activity [143] (Table 2). Alpha-lipoic acid has many formulations and different administration routes to be assessed on microvascular complications; as an example, an aqueous formulation showed to diminish fluorescein leakage in the eye of streptozotocin-induced diabetic rats [144]. Alphalipoic acid's beneficial properties were also assessed in mitochondrial metabolism, as said before, given its importance in DR. Preclinical studies assess mitochondrial function and regulation measured by its transcriptional factor, peroxisome proliferator-activated receptor- $\gamma$ (PPAR- $\gamma$ ) coactivator$1 \alpha$, and nuclear respiratory factor 1 (NRF1); a beneficial effect of alpha-lipoic acid was preventing the loss of mitochondrial copy number and increasing gene transcripts of PPAR- $\gamma$ and NRF1 [145]. Clinical and preclinical studies have showed efficacy of lipoic acid as monotherapy or combined antioxidant therapy in DR by measuring different outcomes such as mitochondrial damage through the production of ROS or retinal damage [146, 147]. Clinically, alpha-lipoic acid may have a protective role [148] but this needs to show efficacy on patients who have already developed later stages of DR because it has not shown any effect on macular edema [149].

4.7. Curcumin. Curcumin is a unique polyphenol found in turmeric (Curcuma longa) and used as spice, food coloring, and traditional medicine due to its antioxidant and antiinflammatory properties [150]. Curcumin is a crystalline orange-yellow color compound [151]. The World Health Association stated an acceptable daily intake of $0-3 \mathrm{mg} / \mathrm{kg}$ as a food additive [152]; yet, unfortunately, turmeric has a poor bioavailability due to poor absorption and rapid metabolism and elimination: even though multiple agents have been used to increase its bioavailability, curcumin has proved to be safe in humans with low toxicity and be well tolerated with doses as high as $12 \mathrm{~g} /$ day in clinical trials [153]. This "golden spice" has been thoroughly studied due to its many properties and potential therapeutically targets, being described as pharmacodynamically "fierce" yet pharmacoki- netically "weak" by not having conclusive beneficial clinical effects [154].

In diabetes, curcumin has shown to have the ability to increase insulin sensitivity and to exert a hypocholesterolemic and hypoglycemic effect by normalization of triglyceride, cholesterol, OS status, lipid peroxidation, TNF- $\alpha$, and free fatty acids in preclinical studies [155]. In DR, curcumin adjuvant therapy restores retinal antioxidant capacity, increasing antioxidant enzymes and their expression, like SOD and catalase, as well as reducing free radicals [156]. In vitro, curcumin showed a potentially synergic effect by boosting MnSOD expression and activity when studied in endothelial progenitor cells [157]. Also, regarding inflammation, curcumin abolishes the expression of important proinflammatory cytokines such as TNF- $\alpha$, VEGF, and ICAM-1 in animal models, and it can inhibit protein kinase C- $\beta[155,158]$ and ameliorate the inflammatory effects of high-glucose exposure by decreasing proinflammatory cytokines via the Akt/mTOR pathway [159]. These anti-inflammatory properties link curcumin as a potent antiangiogenic agent decreasing VEGF expression (see Figure 2) and playing an important role in DR by inhibiting migration of retinal human endothelial cells by decreasing stromal derived factor-1 [160].

The Nrf2 interacts with Kelch-like ECH-associated protein (Keap-1), the molecule associated with OS-induced damage; however, in response to OS, Nrf2 translocates to the nucleus from cytosol and binds antioxidant/electrophile response element in the promoters of target genes such as NADPH [161]. Curcumin is a promising alternative for the adjuvant therapy in DR although it has yet to show its effects in vivo in clinical studies $[162,163]$.

4.8. Polyphenols: Anthocyanins and Resveratrol. A subgroup of flavonoid polyphenols, anthocyanins are water-soluble pigments that give the blue, purple, and red coloration of many fruits and flowers. Among over 20 anthocyanidins that are known, only 6 of them are widely distributed in human diet: cyanidin, delphinidin, pelargonidin, peonidin, malvidin, and petunidin. They can be found primarily in berry fruits from either Vitaceae or Rosaceae family or dark-colored vegetables and cereals [164]. Anthocyanin metabolism consists mainly in degradation to phenolic acid and subsequently to other stable water compounds [165]. Although anthocyanins were reported to have low bioavailability, their metabolites have been detected in much higher concentrations (by 42-fold) in plasma [166] and have been found in eye-related tissues [167]. These compounds have been studied in different pathologies involving OS and even cancer due to several signaling pathways including mitogen-activated protein kinase, NF- $\kappa \beta$, AMP-activated protein kinase, apoptosis, and autophagy [168]. Some of the effects of anthocyanins on DM are as follows: the ability to regulate the expression and translocation of GLUT4 receptor, to increase the activation of PPAR- $\gamma$ and AMP-activated protein kinase, and to inhibit intestinal enzyme $\alpha$-glucosidase and pancreatic $\alpha$-amylase [169]. Anthocyanins have been assessed in preclinical studies exceeding their role as antioxidants in retinal pigment epithelium by neutralizing ROS, inhibiting diabetes-induced retinal 
abnormalities, and having a protective role in neurodegeneration regarding the retina in $N$-methyl-N-nitrosourea-induced damaged rats [170]. Malvidin and its glycosides increase SOD and catalase in high glucose-induced human retinal capillary endothelial cells, protecting these cells from OS-induced damage, and by anti-inflammatory properties due to inhibition of ICAM- 1 and NF- $\kappa \beta$ (see Table 2) [171]. Cyanidin and orthodihydroxy groups of anthocyanins can inhibit lipid peroxidation by chelating metal ions [172], and other anthocyanins can facilitate nuclear translocation of Nrf2, inducing the activation of this redox-sensitive activation factor [173].

Resveratrol (3,5,4' -trihydroxy-trans-stilbene) is another potential adjuvant agent in the aid of DR: resveratrol is an important nonflavonoid polyphenol, the most abundant polyphenol in red wine in concentrations of $8-25 \mu \mathrm{M}$, which is a typical component of the Mediterranean diet [42]. Resveratrol has been extensively studied for its wide variety of biological actions such as antioxidative and anti-inflammatory properties important for DR, exerting potentially cardioprotective, neuroprotective, and chemotherapeutic properties [174]. Focusing mainly on DR, resveratrol has a protective role involving OS-induced apoptosis by reducing intracellular ROS through the AMPK/Sirt1/PGC$1 \alpha$ pathway [175] and, like the other polyphenols, is as an activator of Nrf2 [173]. In in vitro studies with human retinal pigment epithelial cells (ARPE-19 cells), resveratrol showed an inhibitory effect on inflammatory cytokines such as IL-6 and IL-8 [176], and in preclinical studies, resveratrol also inhibited VEGF through yet another pathway, by increasing the activity of paraoxonase 1 (PON1) which is involved in protecting endothelial cells [177] and inhibiting the VEGF expression [178]. Unlike other nutraceuticals, resveratrol exhibits a biological property to act on a more directed manner against apoptosis, mainly on Müller cells by upregulating the microRNA-29b, and so downregulating specific protein 1 expression [179] and directly inhibiting caspase- 8 and caspase- 3 as seen in Figure 2 [180]. Given all these beneficial effects, more clinical interventions are needed to prove or assess these effects clinically in DR [181].

4.9. Ubiquinone. Ubiquinone, also known as coenzyme-Q (CoQ10) is a mobile component of mitochondrial electron transport chain. The CoQ10 is present in all cells and membranes and is necessary for mitochondrial energy production [182]. The richest dietary sources of CoQ10 are meat, migratory fish, and some oils and nuts, and the recommended dose in supplements go from 50 to $150 \mathrm{mg}$ [183]. The CoQ10 is the only lipid-soluble antioxidant that animal cells synthesize de novo in the body [184]; and, remarkably, as a combined adjuvant therapy, CoQ10 can recycle and regenerate other antioxidants such as tocopherol and ascorbate [185]. CoQ10 also protects against endothelial dysfunction by activating endothelial nitric oxide synthase and mitochondrial oxidative phosphorylation [185].

As a coadjuvant therapy, it has been assessed alongside the Mediterranean diet in elderly population, and when $200 \mathrm{mg}$ of CoQ10 per day was added, the oxidative and inflammatory states were diminished compared to the Mediterranean and Western diets [186]. A liquid formulation with ubiquinol $100 \mathrm{mg} /$ day was given over 12 weeks in T2DM patients showing increased levels of antioxidant biomarkers like SOD, catalase, and GPx, but not MDA, compared to placebo [187], compared to a similar study done in patients with T2DM and DN where MDA and AGEs levels were diminished [188]. Limited studies have been done in patients with DR regarding the addition of CoQ10. In a clinical study, CoQ10 supplementation for 6 months improved OS state by increasing total antioxidant capacity and decreasing lipid peroxidation [189]. Overall, CoQ10 seems to have a promising therapeutic potential in the aid of diabetes-related complications primarily for its antioxidant properties; and it has been shown to improve visual acuity in patients with agerelated macular degeneration, as well as protecting ganglion cell death in glaucoma models [190].

4.10. Omega-3 Fatty Acids. Omega-3 is an important product from the Mediterranean diet [33], as it is one of the main reasons why this diet is so commonly healthy. Omega fatty acids encompass three major subtypes: omega- 3 , omega- 6 , and omega-9 fatty acids. Among these, omega- 3 is subcomposed of three more types: alpha-linoleic acid, eicosapentaenoic acid, and docosahexaenoic acid [191]. Omega-3 fatty acids can be found in fish, and based on observational data, an intake of $500 \mathrm{mg} / \mathrm{d}$ is associated with a decreased risk of a sight-threatening DR [33]. This can be explained by several mechanisms. Low-chain PUFAs have an important role for the function and survival of photoreceptors, and they also inhibit cytokine-induced NF- $\kappa \beta$ activation and translocation, as illustrated in Figure 2. In preclinical studies, they also have shown to decrease inflammation in the eye and their lipoxins, resolvins, and protectins which are derived from these fatty acids that have antiangiogenic capabilities [192, 193]. Preclinical studies have demonstrated that a flaxseed oil diet, another natural source of omega- 3 fatty acid, does increase the expression of G-protein-coupled receptor 120 (GPR120), a receptor of omega-3, but not GPR40 [194] (see Table 2). Remarkably, omega-3 PUFAs suppress ER stress in adipocytes by AMPK activation, and resolvin D1, a family derived from eicosapentaenoic and docosahexaenoic acids, attenuates ER stress-induced apoptosis and decreases caspase-3 activity [195].

Overall, omega- 3 fatty acids show a remarkable potential in the prevention of progression in DR, primarily in the early stages [196].

4.11. Erianin. Erianin (2-methoxy-5-[2-(3c4c5-trimethoxyphenyl)ethyl]-phenol), a relatively newer nutraceutical not yet explored deeply in DR, is another natural product, derived from Dendrobium chrysotoxum, an herb of the Orchidaceae family. Used mainly in Chinese traditional medicine as antipyretic or analgesic, indexed in the Chinese pharmacopoeia, it contains two phenyl rings linked by a 2 -carbon bridge with methoxyl substitutions on the phenyl rings [197, 198].

Erianin has been studied mainly for its antiangiogenic properties. In preclinical studies, $100 \mathrm{mg} / \mathrm{kg}$ per day of erianin induced growth delay in tumors [199]. In 2015, erianin was first introduced as a DR therapy option, by inhibiting the NF- $\kappa \beta$ signaling pathway, thus inhibiting retinal 
inflammation in preclinical studies [198, 199]. Nevertheless, clinical studies are still needed to assess its clinical relevance in DR and its potential use as a concomitant therapy in this disease.

4.12. Melatonin. Melatonin, $\mathrm{N}$-acetyl-5-methoxytryptamine, is a ubiquitous molecule found in almost all living organisms. In mammals, melatonin is centrally produced by the pineal gland and is directly released in the blood as a hormone [200], predominantly at night, known to promote sleep products and regulate circadian rhythms. Melatonin has been reported to regulate important molecular pathways related to DR such as apoptotic, antiangiogenic, anti-inflammatory, and Nrf2 pathways by being one of the most powerful antioxidants [200, 201]. The effects of melatonin in reduction of OS are through free radical scavenging activity and stimulating antioxidant enzymes like GR, GPx, SOD, and catalase and by suppressing activity of prooxidant enzymes like nitric oxide synthase and its inducible form (iNOS) and cyclooxygenase-2 [202]. In preclinical studies with streptozotocin-induced prediabetic rats, $85 \mu \mathrm{g} / \mathrm{animal} / \mathrm{day}$ of melatonin improved fasting glucose and serum insulin levels and had a significant decrease in retinal thiobarbituric acid-reactive substances, iNOS, VEGF, and matrix metalloproteinase 9 [203]. In another study in a model with oxidative glutamate toxicity in combination with buthionine sulfoximine, intravitreal injections of melatonin showed a protective effect against apoptosis of retinal ganglion cells, acting as a neuroprotective agent [204] (see Figure 2). Lower salivary melatonin peak levels have been reported in patients with DM compared to nondiabetic patients [205]. Melatonin can ameliorate inflammation, reducing inflammatory cytokines and iNOS through inhibition of NF- $\kappa \beta$, and may reduce ER-induced apoptosis and autophagy [202].

As an adjuvant combined therapy alongside zinc acetate, it has shown to improve postprandial and fasting glucose levels [206]. More clinical interventions are needed to assess its effect in DR: melatonin shows a promising beneficial effect in this disease, as summarized in Table 2.

4.13. Combined Therapies. The approach of combined therapies (see Figure 3) as an adjuvant therapy for early stages of DR is to combine the best possible nutraceuticals aimed at the key mentioned biomechanisms such as OS and inflammation, to delay progression to PDR without leaving behind the established glycemic control. Many options have been already rehearsed in clinical stages (shown in Table 3), even using compounds not mentioned in this review, like Ginkgo biloba, which may have a protective role in early DR $[4,207]$. Nevertheless, preclinical approaches assessing different combinations have not shown statistical significance on their primary outcomes in clinical studies whereas some preclinical studies do. When considering new therapeutic strategies to treat DR, targeting a different mechanism other than VEGF should be the aim [178] to focus on, given just one single option may not be the most optimal for our patients. A recent metaanalysis regarding the use of Chinese herbs as a single adjuvant therapy for DR, like erianin, does not conclude that a single therapy can be beneficial by itself. However, a com-

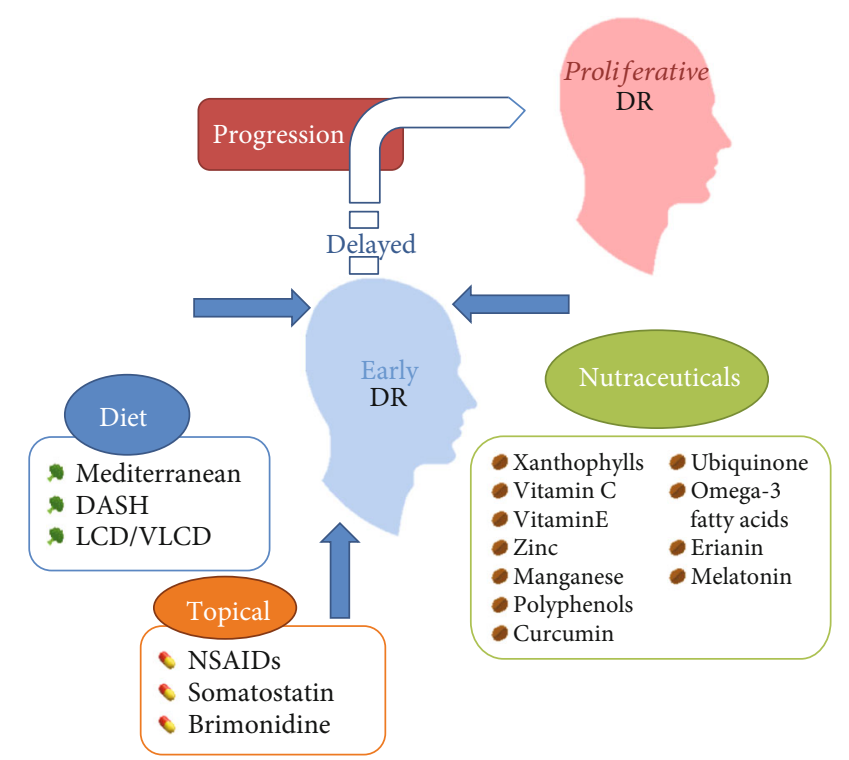

FIgURE 3: A model of nontraditional therapies focused for diabetic retinopathy to diminish its progression from early to proliferative stages. Represents the two main topics focusing on diet and nutraceuticals either alone or combined, both as an alternative adjuvant therapy for DR. Abbreviations: DR: diabetic retinopathy; DASH: Dietary Approaches to Stop Hypertension; LCD: lowcalorie diet; VLCD: very low-calorie diet; NSAIDs: nonsteroidal anti-inflammatory drugs.

bined use of drugs may improve the synergic effect, supporting the use of combined adjuvant therapies as a field to be explored for the management of DR [4, 208]. A mixture of supplements, reviewed by Tabatabaei et al., may have an additive effect, diminishing mitochondrial dysfunction, OS, and endothelial damage [209]. More clinical interventions are needed to assess possible therapeutic combinations for DR treatment considering modifications in OS, inflammation, neovascularization, neurodegeneration, and mitochondrial damage pathways.

4.14. Nonsteroidal Anti-Inflammatory Drugs. Inflammation has proven to be an essential mechanism in the genesis of DR. In a recent study in vitreous tissue of patients with DR, inflammation biomarkers such as IL- $1 \beta$, TNF- $\alpha$, IL-18, IL-6, caspase-1, interferon gamma (IFN- $\gamma$ ), prostaglandin $\mathrm{E}_{2}\left(\mathrm{PGE}_{2}\right)$, and VEGF were increased in comparison to nondiabetic patients [223]. This emphasizes the therapeutic potential of nonsteroidal anti-inflammatory drugs (NSAIDs) as an adjuvant therapy in DR.

Topical NSAIDs are delivered through the posterior segment from 2 different routes: corneal and noncorneal pathways. The first one is limited due to precorneal space by lacrimation and ionization of acids in the pharmaceutical compounds, and also, the reduced fraction that reaches the anterior chamber is cleared by the physiologic flow of aqueous humor, and finally, the iridolenticular diaphragm creates a concentration gradient limiting even more its penetration to the posterior chamber. The noncorneal pathway involved penetration through the conjunctiva and sclera, which may be a possible route to uveal and to retinal tissues [224]. Even 
TABLE 3: Clinical and preclinical studies using combined antioxidant therapies. Although they do not share the same primary outcomes, these studies all aim to establish significance in the treatment of the onset of DR, sharing the thought of looking for a nontraditional but effective adjuvant therapy to diminish DR progression, showing purely combined antioxidant therapies and adjuvant to metformin or statins.

\begin{tabular}{llll}
\hline Design & Intervention & Results & Reference \\
\hline
\end{tabular}

(i) Group 1: zinc (20 mg), magnesium (250 mg), vitamin C (200 mg), and vitamin E (100 mg)

(ii) Group 2: zinc, magnesium, vitamin $\mathrm{C}$, vitamin $\mathrm{E}$, Clinical trial vitamin $B_{1}(10 \mathrm{mg})$, vitamin $B_{2}(10 \mathrm{mg})$, vitamin $B_{6}$ $(10 \mathrm{mg})$, biotin $(200 \mu \mathrm{g})$, vitamin $\mathrm{B}_{12}(10 \mu \mathrm{g})$, and folic acid (1 mg)

No difference was observed between the three groups. Short-termed combined adjuvant therapy did not show efficacy in MNSI score for diabetic neuropathy

(iii) Group 3: placebo

(i) Group 1: oral glucose (75 g)

Clinical trial (ii) Group 2: oral glucose, vitamin C (2 g), and vitamin E (800 IU)

FMD did not change significantly after glucose plus vitamins.

12 weeks of $6 \mathrm{~d}$ /week of exercise with:

(i) Group 1: vitamin E (400 IU of D- $\alpha$-tocopherol) plus 3 tea There was a decrease of waist circumferences and

Clinical trial sachets 3 per/d in $240 \mathrm{~mL}$ of water containing $1.5 \mathrm{~g}$ per sachet

fasting glucose level; erythrocyte catalase activities

(ii) Group 2: placebo

(i) Group 1: vitamin E (800 IU/d), vitamin C (500 mg/d), and $\alpha$-lipoic acid $(900 \mathrm{mg} / \mathrm{d})$

Clinical trial

(ii) Group 2: CoQ10 3 (400 mg) 3 per day

increased in the combined adjuvant therapy group.

Antioxidants did not alter the cerebrospinal fluid biomarkers

(iii) Group 3: placebo

(i) Group 1: Ginkgo biloba dry extract

$\begin{array}{ll}\text { Clinical trial } & \text { (ii) Group 2: } \alpha \text {-lipoic acid and vitamin C } \\ & \text { (ii) Group 3: papaverine chlorhydrate and vitamin E }\end{array}$

(iv) Group 4: placebo

There was no statistical difference in audiometry, speech recognition threshold, or percentage index of speech recognition in patients with presbycusis

(i) Group 1: CoQ10 (400 mg)

(ii) Group 2: lutein $(10 \mathrm{mg})$, astaxanthin $(4 \mathrm{mg})$, zeaxanthin Mitochondrial dysfunction measured by SMF of

Clinical trial (1 mg), vitamin C (180 mg), vitamin E (30 mg), zinc (20 mg), and copper (1 mg). platelets and its hydrolytic activity increased in the CoQ10 and combined therapy group

(iii) Group 3: placebo

(i) Group 1: intravitreal ranibizumab $(0.5 \mathrm{mg} / 0.05 \mathrm{~mL})$

(ii) Group 2: intravitreal ranibizumab with the added DHA supplementation group which is composed of the following: concentrated oil in omega- 3 fatty acids (500 mg), triglyceride-bound (350 mg), eicosapentaenoic Clinical trial acid $(42.5 \mathrm{mg})$, docosapentaenoic acid $(30 \mathrm{mg})$, vitamin $\mathrm{B}_{1}(0.37 \mathrm{mg})$, vitamin $\mathrm{B}_{2}(0.47 \mathrm{mg})$, vitamin $\mathrm{B}_{3}(5.3 \mathrm{mg}$ $\mathrm{NE})$, vitamin $\mathrm{B}_{6}(0.47 \mathrm{mg})$ vitamin $\mathrm{B}_{9}(66.7 \mu \mathrm{g})$, vitamin $\mathrm{B}_{12}(0.83 \mu \mathrm{g})$, vitamin C $\left.26.7 \mathrm{mg}\right)$, vitamin E $(4 \mathrm{mg})$, zinc Statistically significant decrease of central subfield macular thickness in favor of the combined DHA supplementation group, but improvement in the best-corrected visual acuity measured in ETDRS (1.66 mg), copper $(0.16 \mathrm{mg})$, selenium $(9.16 \mu \mathrm{g})$, manganese $(0.33 \mathrm{mg})$, lutein $(3 \mathrm{mg})$, zeaxanthin $(0.3 \mathrm{mg})$, and glutathione $(2 \mathrm{mg})$

(i) Group 1: normal diet with added supplementation of the following: vitamin C (300 mg), vitamin $\mathrm{D}_{3}$ (10,000 IU), vitamin E (300 IU), fish oil (1.6 g), eicosapentaenoic acid (650 mg), docosahexaenoic acid (500 mg), benfotiamine

Preclinical (1 g), $\alpha$-lipoic acid (750 mg), tocomin (200 mg), zeaxanthin (40 mg), lutein (20 mg), resveratrol, green tea, turmeric root (curcumoids), $\mathrm{N}$-acetyl-cysteine, Pycnogenol ${ }^{\otimes}$ pine bark, grape seed extract, CoQ10, zinc was not statistically significant.

The group receiving the adjuvant supplement showed decreased capillary cell apoptosis, attenuated retinal damage, OS, mitochondrial damage, and inflammation with no impact on $(2.65 \mathrm{~g})$, and soybean oil

(ii) Group 2: no supplementation 
TABLe 3: Continued.

\begin{tabular}{|c|c|c|c|}
\hline Design & Intervention & Results & Reference \\
\hline Preclinical & $\begin{array}{l}\text { (i) Group 1: control group } \\
\text { (ii) Group 2: diabetic rats left for } 3 \text { days } \\
\text { (iii) Group 3: untreated diabetic rat group } \\
\text { (iv) Group 4: diabetic rats treated with CoQ10 (10 mg/kg } \\
\text { b.wt.) } \\
\text { (v) Group 5: diabetic rats treated with niacin }(40 \mathrm{mg} / \mathrm{kg} \\
\text { b.wt.) } \\
\text { (vi) Group 6: CoQ10 and niacin } \\
\text { (vii) Group 7: glibenclamide (5 mg/kg b.wt.) } \\
\text { (viii) Group 8: donepezil hydrochloride ( } 3 \mathrm{mg} / \mathrm{kg} \text { b.wt.) } \\
\text { (ix) Group 9: glibenclamide and donepezil hydrochloride }\end{array}$ & $\begin{array}{l}\text { CoQ10 and niacin improved glucose and insulin } \\
\text { levels, an improvement of neurotransmitters and } \\
\text { OS biomarkers. Decrease in levels of ICAM, } \\
\text { VCAM, and Ang-II and finally decreased levels of } \\
\text { TNF- } \alpha \text { and caspase-3 }\end{array}$ & [218] \\
\hline Preclinical & $\begin{array}{l}\text { (i) Group 1: control group } \\
\text { (ii) Group 2: DM and streptozotocin vehicle } \\
\text { (iii) Group 3: DM+MPO }(2 \mathrm{mg} / \mathrm{kg} \mathrm{bw}) \\
\text { (iv) Group 4: DM+MPO }(10 \mathrm{mg} / \mathrm{kg} \mathrm{bw}) \\
\text { (v) Group 5: DM+MPO }(50 \mathrm{mg} / \mathrm{kg} \text { bw) }\end{array}$ & $\begin{array}{l}\text { MPO groups showed a reduced aldose reductase } \\
\text { activity and reduced expression of p38MAPK and } \\
\text { ERK } 1 / 2 \text { in rat lens. Medium ( } 10 \mathrm{mg} / \mathrm{kg} \text { bw }) \text { dosing } \\
\text { showed a significant decrease in GPx activity in } \\
\text { lens of diabetic rats }\end{array}$ & [219] \\
\hline Preclinical & $\begin{array}{l}\text { (i) Group 1: ascorbic acid }(100 \mathrm{mg} / \mathrm{kg}) \\
\text { (ii) Group 2: ascorbic acid }(200 \mathrm{mg} / \mathrm{kg}) \\
\text { (iii) Group 3: diclofenac sodium }(5 \mathrm{mg} / \mathrm{kg}) \\
\text { (iv) Group 4: diclofenac sodium and ascorbic acid } \\
(100 \mathrm{mg} / \mathrm{kg}) \\
\text { (v) Group 5: diclofenac sodium and ascorbic acid } \\
\text { (200 mg/kg) } \\
\text { (vi) Group 6: prednisolone }(5 \mathrm{mg} / \mathrm{kg}) \\
\text { (vii) Group 7: prednisolone and ascorbic acid }(100 \mathrm{mg} / \mathrm{kg}) \\
\text { (viii) Group 8: prednisolone and ascorbic acid }(200 \mathrm{mg} / \mathrm{kg}) \\
\text { (ix) Group 9: atorvastatin }(8 \mathrm{mg} / \mathrm{kg}) \\
\text { (x) Group 10: atorvastatin and ascorbic acid }(100 \mathrm{mg} / \mathrm{kg}) \\
\text { (xi) Group 11: atorvastatin and ascorbic acid }(200 \mathrm{mg} / \mathrm{kg}) \\
\text { (xii) Group 1: control }\end{array}$ & $\begin{array}{l}\text { The formalin- and carrageenan-induced } \\
\text { inflammation was best inhibited by the } \\
\text { combination of diclofenac and ascorbic acid }\end{array}$ & [220] \\
\hline
\end{tabular}

(i) Group 1: low-fat diet

(ii) Group 2: high-fat diet treated with metformin (250 mg/kg/day)

Preclinical (iii) Group 3: high-fat diet treated with resveratrol (100 mg/kg/day)

Significant restoration of AMPK with combined therapy. Metformin alone did not induce AMPK

(iv) Group 4: high-fat diet treated with metformin and resveratrol

$\begin{array}{ll}\text { Retrospective } & \text { (i) Group 1: statin consumption } \\ & \text { (ii) Group 2: statin with vitamin C }\end{array}$
Statins decrease complication rate of NPDR, and an increased protective effect when vitamin $\mathrm{C}$ was added

(i) Group 1: placebo and metformin (2550 mg/day)

Clinical trial (ii) Group 2: melatonin (10 mg), zinc (50 mg), and metformin

(iii) Group 3: melatonin and zinc
Melatonin and zinc, alone or adjunct to metformin improved fasting and postprandial glucose levels

Abbreviations: MNSI: Michigan Neuropathy Screening Instrument; FMD: flow-mediated dilatation; SMF: submitochondrial membrane fluidity; ETDRS: Early Treatment Diabetic Retinopathy Study; CoQ10: coenzyme-Q; OS: oxidative stress; ICAM-1: intercellular adhesion molecule-1; VCAM-1: vascular cell adhesion molecule-1; TNF- $\alpha$ : tumor necrosis factor-alpha; DM: diabetes mellitus; MPO: Mangifera indica L. and Polygonum odoratum L. (extract); p38MAPK: p38 mitogen-activated protein kinase; ERK1/2: extracellular signal-related protein kinase 1/2; GPx: glutathione peroxidase; AMPK: AMP protein kinase; NPDR: nonproliferative diabetic retinopathy.

with this complexity, topical NSAIDs such as indomethacin, bromfenac, and nepafenac have all shown to reduce $\mathrm{PGE}_{2}$ levels in prospective clinical studies [225]. Topical nepafenac has been the most evaluated NSAID, to our knowledge. When evaluated in noncentral diabetic macular edema, nepafenac showed no statistical difference in retinal volume measured by optical coherence tomography with a therapy consisting of 3 applications daily for 12 months [226]. Nevertheless, applying 3 times daily in one eye did show a reduction effect in retinal thickness in another shorter study alongside a narrowing effect on the retinal arteriole diameter from the first week of treatment [227]. The use of NSAIDs is safe and well tolerated. Corneal epithelial damage and punctate keratitis are mainly sporadic adverse side effects 
[228] associated with topical ophthalmic medications containing preservatives; however, adverse side effects could be more common in patients with history of complicated corneal surgery, diabetes, dry eye syndrome, and rheumatoid arthritis [224].

4.15. Other Adjuvant Therapies. Similar to NSAIDs, other systemic medications have been assessed in DR. Having the clinical perspective of a T2DM patient whose progression of the disease has reached development of DR, it is expected that these patients are already taking several medications whether for DM itself or related disorders from metabolic syndrome, like dyslipidemia or hypertension. A recent meta-analysis of glucose-lowering medications indicated an increased risk of DR with sulfonylureas, and there is no association with dipeptidyl peptidase 4 inhibitors (DPP-4i), glucagon-like peptide-1 receptor agonist (GLP-1RA), and sodium-glucose transport protein 2 (SGLT2); still, the latter was associated with the lowest probability to develop DR complications [229]. Regarding dyslipidemia, contradictive information has been found with its association to DR and its complication as shown from a meta-analysis that even though lipid profile was worse in patients who developed diabetic macular edema, no higher risk to develop a more severe stage nor worsening of hard exudates was shown [226]. Nonetheless, in recent cohort studies, statin therapy was associated with a decreased risk of DR and its complications compared to a population not taking statins [230, 231].

Another pathological implication involved in the genesis of DR is the renin-angiotensin-aldosterone system (RAAS), more specifically, angiotensin II and aldosterone which are involved with retinal angiogenesis, vascular leakage, neurovascular regulation, edema, and inflammation $[232,233]$. This leads to the hypothesis of the usage of RAAS inhibitors in DR as a possible therapy option; and in normotensive patients, either angiotensin-converting enzyme inhibitors or angiotensin receptor blockers showed a decreased risk for DR progression and increased possible regression, but this was not the case with hypertensive patients [234].

Fenofibrates have also been studied in DR in clinical and preclinical studies. In a preclinical study, fenofibrate attenuated OS and inflammation in Müller cells by activating Nrf2 (as seen in Figure 2) and by inhibiting nucleotidebinding domain, leucine-rich repeat-containing receptor, and pyrin domain-containing 3 (NLRP3) inflammasome activation [235]. In a retrospective cohort study, fibrates were associated with a reduced progression of DR [236] and also protection of the retinal nerve fiber layer loss associated with early neurodegeneration in DR, by showing a thicker layer compared to T2DM patients who did not take fibrates [237]. A review regarding the usage of fenofibrates in DR showed a beneficial effect independently to its ability to lower lipids or triglycerides and recommended a maximum dose of $200 \mathrm{mg}$ per day, or $67 \mathrm{mg}$ if impaired kidney function is present, though fenofibrates are contraindicated in severe stages of DN [238]. Fenofibrates may have the potential to reduce the progression of $\mathrm{DR}$, but more information is needed to either confirm or negate their efficacy [239, 240].

An approach that stands out is the administration of topical neuroprotective agents for DR, primarily somatostatin and brimonidine, again highlighting the importance of neurodegeneration in DR. The hypothesis involving the inhibition of growth hormone and insulin-like growth factor 1 (IGF-1) that could diminish DR progression began in the early 2000s but caught more attention after the EUROCONDOR study [241]. Somatostatin analogues may play a role in DR by preventing neovascularization, vascular leakage, and neurodegeneration independently to IGF-1 [242]. Brimonidine, on the other hand, is a drug aimed at lowering intraocular pressure in patients with ocular hypertension by improving microcirculation and increasing ocular perfusion [243]. It also diminishes cell injury through elimination of glutamate-induced excitotoxicity of $N$-methyl-D-aspartate receptors [244]. Both drugs by topical administration showed a protective effect on DR; somatostatin did so by dilating central retinal arteriolar equivalent, and venular dilation with both drugs in EUROCONDOR's 2-year therapy [245], and it may prevent worsening of preexisting neurodysfunction [246].

4.16. Future Perspectives. Different adjuvant therapies have been evaluated in this review focusing mainly on diminishing the progression of DR, through other routes, such as using light stimulation or pharmacological strategies to shift photoreceptors into less energy-consuming metabolic states [247]. The complexity to deliver cost-effective drugs to the posterior segment of the eye has led to novel approaches [248]. A new drug delivery system with sustained-release implants, nanotechnology [249, 250], and lysosomes is being developed. A combination therapy of novel inhibitors targeting the molecules beyond VEGF may be more effective in treating DME in the coming years, such as the KininKallikrein system or Tie-2, the latter being the receptor tyrosine kinase of angiopoietins 1 and 2 [251, 252].

In addition, different technologies such as intravitreal implants, devices in the suprachoroideal space, or use of magnetic field to deliver drugs to the posterior segment of the eye have been reviewed with promising results, which have yet to show efficacy in further studies [248]. Ultimately, the aim is to be able to offer a cost-effective and noninvasive therapy to prevent DR consequential blindness, aiming at neovascularization [253] or as shown in this article inflammation and/or OS (preferably in a more localized manner is the future in the management of DR). An example of this is the encapsulated form in liposomes of anthocyanins which increased their bioefficacy [166] or gold-coated nanoparticles of resveratrol which showed a beneficial effect by lowering inflammatory cytokines and decreasing angiogenesis in streptozotocin-induced diabetic rats [254]; more biomarkers are being studied, such as pentraxin 3, which is another serum biomarker of DR that was associated with its development and progression with high sensitivity levels, indicating more advanced stages of the disease [255], broadening the horizon in the management of DR. 


\section{Conclusion}

DR is a progressive disease, a consequence of DM that can ultimately lead to visual disability. The physiopathology of $\mathrm{DR}$ is involved in a complex variety of biochemical pathways such as OS and inflammation as main therapeutic targets and also neurodegeneration, apoptosis, autophagy, lipid metabolism abnormalities, ER stress, and ultimately angiogenesis. The approach of this article is to focus on the alreadyknown diets, nutraceuticals, and different compounds as an adjuvant approach in the treatment DR to diminish its progression.

We expect to focus our future perspectives for interventions assessing different combined adjuvant therapies in the pathways described in this multifactorial disease, to simultaneously stop or diminish the progression of DR from early stages to more severe ones preventing the visual impairment in patients with DM.

\section{Conflicts of Interest}

All authors of this review article declare no conflict of interest.

\section{References}

[1] O.-M. Cecilia, C. G. José Alberto, N. P. José et al., "Oxidative stress as the main target in diabetic retinopathy pathophysiology," Journal Diabetes Research, vol. 2019, article 8562408, 21 pages, 2019.

[2] N. Maniadakis and E. Konstantakopoulou, "Cost effectiveness of treatments for diabetic retinopathy: a systematic literature review," PharmacoEconomics, vol. 37, no. 8, pp. 995-1010, 2019.

[3] L. Z. Heng, O. Comyn, T. Peto et al., "Diabetic retinopathy: pathogenesis, clinical grading, management and future developments," Diabetic Medicine, vol. 30, no. 6, pp. 640-650, 2013.

[4] H. W. Zhang, H. Zhang, S. J. Grant, X. Wan, and G. Li, "Single herbal medicine for diabetic retinopathy," Cochrane Database of Systematic Reviews, 2018.

[5] I. M. Stratton, E. M. Kohner, S. J. Aldington et al., "UKPDS 50: risk factors for incidence and progression of retinopathy in type II diabetes over 6 years from diagnosis," Diabetologia, vol. 44, no. 2, pp. 156-163, 2001.

[6] N. Sayin, N. Kara, and G. Pekel, "Ocular complications of diabetes mellitus," World Journal of Diabetes, vol. 6, no. 1, pp. 92-108, 2015.

[7] M. Whitehead, S. Wickremasinghe, A. Osborne, P. van Wijngaarden, and K. R. Martin, "Diabetic retinopathy: a complex pathophysiology requiring novel therapeutic strategies," Expert Opinion on Biological Therapy, vol. 18, no. 12, pp. 1257-1270, 2018.

[8] T. S. Kern, D. A. Antonetti, and L. E. H. Smith, "Pathophysiology of diabetic retinopathy: contribution and limitations of laboratory research," Ophthalmic Research, vol. 62, no. 4, pp. 196-202, 2019.

[9] F. Semeraro, F. Morescalchi, A. Cancarini, A. Russo, S. Rezzola, and C. Costagliola, "Diabetic retinopathy, a vascular and inflammatory disease: therapeutic implications," Diabetes \& Metabolism, vol. 45, no. 6, pp. 517-527, 2019.
[10] O. O. Oguntibeju, "Type 2 diabetes mellitus, oxidative stress and inflammation: examining the links," International Journal of Physiology, Pathophysiology and Pharmacology, vol. 11, no. 3, pp. 45-63, 2019.

[11] R. A. Kowluru, A. Kowluru, M. Mishra, and B. Kumar, "Oxidative stress and epigenetic modifications in the pathogenesis of diabetic retinopathy," Progress in Retinal and Eye Research, vol. 48, pp. 40-61, 2015.

[12] A. Schlotterer, M. Kolibabka, J. Lin et al., "Methylglyoxal induces retinopathy-type lesions in the absence of hyperglycemia: studies in a rat model," The FASEB Journal, vol. 33, no. 3, pp. 4141-4153, 2019.

[13] A. Rübsam, S. Parikh, and P. E. Fort, "Role of inflammation in diabetic retinopathy," International Journal of Molecular Sciences, vol. 19, no. 4, p. 942, 2018.

[14] S. Eid, K. M. Sas, S. F. Abcouwer et al., "New insights into the mechanisms of diabetic complications: role of lipids and lipid metabolism," Diabetologia, vol. 62, no. 9, pp. 1539-1549, 2019.

[15] H. Sankrityayan, M. J. Oza, Y. A. Kulkarni, S. R. Mulay, and A. B. Gaikwad, "ER stress response mediates diabetic microvascular complications," Drug Discovery Today, vol. 24, no. 12, pp. 2247-2257, 2019.

[16] M. Y. Z. Wong, R. E. K. Man, E. K. Fenwick et al., "Dietary intake and diabetic retinopathy: a systematic review," PLoS One, vol. 13, no. 1, article e0186582, 2018.

[17] G. Orwell, "Introduction:standards of medical care in diabetes-2018," Diabetes Care, vol. 41, Supplement 1, pp. S1-S2, 2018.

[18] A. Goday, D. Bellido, I. Sajoux et al., "Short-term safety, tolerability and efficacy of a very low-calorie-ketogenic diet interventional weight loss program versus hypocaloric diet in patients with type 2 diabetes mellitus," Nutrition \& Diabetes, vol. 6, no. 9, article e230, 2016.

[19] S. Baker, G. Jerums, and J. Proietto, "Effects and clinical potential of very-low-calorie diets (VLCDs) in type 2 diabetes," Diabetes Research and Clinical Practice, vol. 85, no. 3, pp. 235-242, 2009.

[20] F. Capstick, B. A. Brooks, C. M. Burns, R. R. Zilkens, K. S. Steinbeck, and D. K. Yue, "Very low calorie diet (VLCD): a useful alternative in the treatment of the obese NIDDM patient," Diabetes Research and Clinical Practice, vol. 36, no. 2, pp. 105-111, 1997.

[21] M. Sasaki, R. Kawasaki, S. Rogers et al., "The associations of dietary intake of polyunsaturated fatty acids with diabetic retinopathy in well-controlled diabetes," Investigative Opthalmology \& Visual Science, vol. 56, no. 12, article 7473, 2015.

[22] S. E. Moss, R. Klein, and B. E. K. Klein, "Alcohol consumption and the prevalence of diabetic retinopathy," Ophthalmology, vol. 99, no. 6, pp. 926-932, 1992.

[23] E. K. Fenwick, J. Xie, R. E. K. Man et al., "Moderate consumption of white and fortified wine is associated with reduced odds of diabetic retinopathy," Journal of Diabetes and its Complications, vol. 29, no. 8, pp. 1009-1014, 2015.

[24] S. E. Moss, R. Klein, and B. E. K. Klein, “The association of alcohol consumption with the incidence and progression of diabetic retinopathy," Ophthalmology, vol. 101, no. 12, pp. 1962-1968, 1994.

[25] C. C. Lee, R. P. Stolk, A. I. Adler et al., "Association between alcohol consumption and diabetic retinopathy and visual 
acuity-the AdRem Study," Diabetic Medicine, vol. 27, no. 10, pp. 1130-1137, 2010.

[26] D. K. Cundiff and C. R. Nigg, "Diet and diabetic retinopathy: insights from the Diabetes Control and Complications Trial (DCCT)," MedGenMed: Medscape General Medicine, vol. 7, no. 1, p. 3, 2005.

[27] M. S. Roy and M. N. Janal, "High caloric and sodium intakes as risk factors for progression of retinopathy in type 1 diabetes mellitus," Archives of Ophthalmology, vol. 128, no. 1, pp. 33-39, 2010.

[28] L. Engelen, S. S. Soedamah-Muthu, J. M. Geleijnse et al., "Higher dietary salt intake is associated with microalbuminuria, but not with retinopathy in individuals with type 1 diabetes: the EURODIAB Prospective Complications Study," Diabetologia, vol. 57, no. 11, pp. 2315-2323, 2014.

[29] C. Horikawa, Y. Yoshimura, C. Kamada et al., "Dietary sodium intake and incidence of diabetes complications in Japanese patients with type 2 diabetes: analysis of the Japan Diabetes Complications Study (JDCS)," The Journal of Clinical Endocrinology \& Metabolism, vol. 99, no. 10, pp. 3635-3643, 2014.

[30] C. Horikawa, Y. Yoshimura, C. Kamada et al., "Is the proportion of carbohydrate intake associated with the incidence of diabetes complications? - an analysis of the Japan Diabetes Complications Study," Nutrients, vol. 9, no. 2, p. 113, 2017.

[31] M. A. Martínez-González, J. Salas-Salvadó, R. Estruch et al., "Benefits of the mediterranean diet: insights from the PREDIMED Study," Progress in Cardiovascular Diseases, vol. 58, no. 1, pp. 50-60, 2015.

[32] A. Díaz-López, N. Babio, M. A. Martínez-González et al., "Mediterranean diet, retinopathy, nephropathy, and microvascular diabetes complications: a post hoc analysis of a randomized trial," Diabetes Care, vol. 38, no. 11, pp. 2134-2141, 2015.

[33] E. Y. Chew, "Dietary intake of omega-3 fatty acids from fish and risk of diabetic retinopathy," JAMA, vol. 317 , no. 21 , pp. 2226-2227, 2017.

[34] PREDIMED Study Investigators, "Intake of total polyphenols and some classes of polyphenols is inversely associated with diabetes in elderly people at high cardiovascular disease risk," The Journal of Nutrition, vol. 146, no. 4, pp. 767-777, 2016.

[35] M. Guasch-Ferré, J. Merino, Q. Sun, M. Fitó, and J. SalasSalvadó, "Dietary polyphenols, Mediterranean diet, prediabetes, and type 2 diabetes: a narrative review of the evidence," Oxidative Medicine and Cellular Longevity, vol. 2017, Article ID 6723931, 16 pages, 2017.

[36] M. L. Pall and S. Levine, "Nrf2, a master regulator of detoxification and also antioxidant, anti-inflammatory and other cytoprotective mechanisms, is raised by health promoting factors," Acta Physiologica Sinica, vol. 67, no. 1, pp. 1-18, 2015.

[37] H. Boeing, A. Bechthold, A. Bub et al., "Critical review: vegetables and fruit in the prevention of chronic diseases," European Journal of Nutrition, vol. 51, no. 6, pp. 637-663, 2012.

[38] M. N. Beidokhti and A. K. Jäger, "Review of antidiabetic fruits, vegetables, beverages, oils and spices commonly consumed in the diet," Journal of Ethnopharmacology, vol. 201, pp. 26-41, 2017.

[39] S. Zafra-Stone, T. Yasmin, M. Bagchi, A. Chatterjee, J. A. Vinson, and D. Bagchi, "Berry anthocyanins as novel antioxidants in human health and disease prevention," Molecular Nutrition \& Food Research, vol. 51, no. 6, pp. 675-683, 2007.

[40] A. E. Millen, R. Klein, A. R. Folsom, J. Stevens, M. Palta, and J. A. Mares, "Relation between intake of vitamins $\mathrm{C}$ and $\mathrm{E}$ and risk of diabetic retinopathy in the Atherosclerosis Risk in Communities Study," The American Journal of Clinical Nutrition, vol. 79, no. 5, pp. 865-873, 2004.

[41] S. Tanaka, Y. Yoshimura, R. Kawasaki et al., "Fruit intake and incident diabetic retinopathy with type 2 diabetes," Epidemiology, vol. 24, no. 2, pp. 204-211, 2013.

[42] M. Finicelli, T. Squillaro, F. di Cristo et al., "Metabolic syndrome, Mediterranean diet, and polyphenols: evidence and perspectives," Journal of Cellular Physiology, vol. 234, no. 5, pp. 5807-5826, 2019.

[43] J. H. Lee, M. K. Oh, J. T. Lim, H. G. Kim, and W. J. Lee, "Effect of coffee consumption on the progression of type 2 diabetes mellitus among prediabetic individuals," Korean Journal of Family Medicine, vol. 37, no. 1, pp. 7-13, 2016.

[44] N. Kumari, "Is coffee consumption associated with agerelated macular degeneration and diabetic retinopathy?" The All Results Journals: Biol, vol. 5, no. 2, pp. 7-13, 2014.

[45] G. Maugeri, A. G. D'Amico, D. M. Rasà et al., "Caffeine prevents blood retinal barrier damage in a model, in vitro, of diabetic macular edema," Journal of Cellular Biochemistry, vol. 118, no. 8, pp. 2371-2379, 2017.

[46] Y. Sharma, S. Saxena, A. Mishra, A. Saxena, and S. M. Natu, "Nutrition for diabetic retinopathy: plummeting the inevitable threat of diabetic vision loss," European Journal of Nutrition, vol. 56, no. 6, pp. 2013-2027, 2017.

[47] M. G. Rossino and G. Casini, "Nutraceuticals for the treatment of diabetic retinopathy," Nutrients, vol. 11, no. 4, p. 771, 2019.

[48] DASH Eating Planhttps://www.nhlbi.nih.gov/health-topics/ dash-eating-plan.

[49] A. Jayedi, K. Mirzaei, A. Rashidy-Pour, M. S. Yekaninejad, M. S. Zargar, and M. R. Akbari Eidgahi, "Dietary approaches to stop hypertension, mediterranean dietary pattern, and diabetic nephropathy in women with type 2 diabetes: a case-control study," Clinical Nutrition ESPEN, vol. 33, pp. 164-170, 2019.

[50] H. F. Lopes, K. L. Martin, K. Nashar, J. D. Morrow, T. L. Goodfriend, and B. M. Egan, "DASH diet lowers blood pressure and lipid-induced oxidative stress in obesity," Hypertension, vol. 41, no. 3, pp. 422-430, 2003.

[51] G. B. de Carvalho, N. L. Dias-Vasconcelos, R. K. F. Santos, P. N. Brandão-Lima, D. G. da Silva, and L. V. Pires, "Effect of different dietary patterns on glycemic control in individuals with type 2 diabetes mellitus: a systematic review," Critical Reviews in Food Science and Nutrition, pp. 1-12, 2019.

[52] A. Medina-Remón, R. Kirwan, R. M. Lamuela-Raventós, and R. Estruch, "Dietary patterns and the risk of obesity, type 2 diabetes mellitus, cardiovascular diseases, asthma, and neurodegenerative diseases," Critical Reviews in Food Science and Nutrition, vol. 58, no. 2, pp. 262-296, 2017.

[53] M. Kawashima, Y. Ozawa, K. Shinmura et al., "Calorie restriction (CR) and CR mimetics for the prevention and treatment of age-related eye disorders," Experimental Gerontology, vol. 48, no. 10, pp. 1096-1100, 2013.

[54] Z. T. Kamuren, C. G. Mcpeek, R. A. Sanders, and J. B. Watkins III, "Effects of low-carbohydrate diet and 
Pycnogeno $^{1 \oplus}$ treatment on retinal antioxidant enzymes in normal and diabetic rats," Journal of Ocular Pharmacology and Therapeutics, vol. 22, no. 1, pp. 10-18, 2006.

[55] M. M. Most, "Estimated phytochemical content of the Dietary Approaches to Stop Hypertension (DASH) diet is higher than in the control study diet," Journal of the American Dietetic Association, vol. 104, no. 11, pp. 1725-1727, 2004.

[56] N. Karanja, T. P. Erlinger, L. Pao-Hwa, E. R. Miller, and G. A. Bray, "The DASH diet for high blood pressure: from clinical trial to dinner table," Cleveland Clinic Journal of Medicine, vol. 71, no. 9, pp. 745-753, 2004.

[57] E. Vasilopoulou, K. Georga, M. Joergensen, A. Naska, and A. Trichopoulou, "The antioxidant properties of Greek foods and the flavonoid content of the Mediterranean menu," Current Medicinal Chemistry: Immunology, Endocrine \& Metabolic Agents, vol. 5, no. 1, pp. 33-45, 2005.

[58] A. Bach-Faig, E. M. Berry, D. Lairon et al., "Mediterranean diet pyramid today. Science and cultural updates," Public Health Nutrition, vol. 14, no. 12A, pp. 2274-2284, 2011.

[59] A. Last and A. Stephen, "Low-carbohydrate diets," American Family Physician, vol. 73, no. 11, pp. 1942-1948, 2006.

[60] T. A. Hussain, T. C. Mathew, A. A. Dashti, S. Asfar, N. al-Zaid, and H. M. Dashti, "Effect of low-calorie versus low-carbohydrate ketogenic diet in type 2 diabetes," Nutrition, vol. 28, no. 10, pp. 1016-1021, 2012.

[61] D. Grotto and E. Zied, "The standard American diet and its relationship to the health status of Americans," Nutrition in Clinical Practice, vol. 25, no. 6, pp. 603-612, 2010.

[62] H. van Wyk and M. Daniels, "The use of very low calorie diets in the management of type 2 diabetes mellitus," South African Journal of Clinical Nutrition, vol. 29, no. 2, pp. 96-102, 2016.

[63] S. Steven and R. Taylor, "Restoring normoglycaemia by use of a very low calorie diet in long- and short-duration type 2 diabetes," Diabetic Medicine, vol. 32, no. 9, pp. 1149-1155, 2015.

[64] S. C. Bain, M. A. Klufas, A. Ho, and D. R. Matthews, "Worsening of diabetic retinopathy with rapid improvement in systemic glucose control: a review," Diabetes, Obesity \& Metabolism, vol. 21, no. 3, pp. 454-466, 2019.

[65] A. Kijlstra, Y. Tian, E. R. Kelly, and T. T. J. M. Berendschot, "Lutein: more than just a filter for blue light," Progress in Retinal and Eye Research, vol. 31, no. 4, pp. 303-315, 2012.

[66] M. le Goff, E. le Ferrec, C. Mayer et al., "Microalgal carotenoids and phytosterols regulate biochemical mechanisms involved in human health and disease prevention," Biochimie, vol. 167, pp. 106-118, 2019.

[67] C. C. Su, C. M. Chan, H. M. Chen et al., "Lutein inhibits the migration of retinal pigment epithelial cells via cytosolic and mitochondrial Akt pathways (lutein inhibits RPE cells migration)," International Journal of Molecular Sciences, vol. 15, no. 8, pp. 13755-13767, 2014.

[68] S.-C. Chao, T. Vagaggini, C. W. Nien, S. C. Huang, and H. Y. Lin, "Effects of lutein and zeaxanthin on LPS-induced secretion of IL- 8 by uveal melanocytes and relevant signal pathways," Journal of Ophthalmology, vol. 2015, Article ID 152854, 7 pages, 2015.

[69] J. M. Silván, M. Reguero, and S. de Pascual-Teresa, “A protective effect of anthocyanins and xanthophylls on UVBinduced damage in retinal pigment epithelial cells," Food \& Function, vol. 7, no. 2, pp. 1067-1076, 2016.

[70] A. G. Murillo and M. L. Fernandez, "Potential of dietary nonprovitamin A carotenoids in the prevention and treatment of diabetic microvascular complications," Advances in Nutrition, vol. 7, no. 1, pp. 14-24, 2016.

[71] R. R. Ambati, S. M. Phang, S. Ravi, and R. Aswathanarayana, "Astaxanthin: sources, extraction, stability, biological activities and its commercial applications-a review," Marine Drugs, vol. 12, no. 1, pp. 128-152, 2014.

[72] L. Cui, F. Xu, M. Wang et al., "Dietary natural astaxanthin at an early stage inhibits $N$-nitrosomethylbenzylamineinduced esophageal cancer oxidative stress and inflammation via downregulation of $\mathrm{NF} \kappa \mathrm{B}$ and $\mathrm{COX} 2$ in $\mathrm{F} 344$ rats," OncoTargets and Therapy, vol. 12, pp. 5087-5096, 2019.

[73] P. T. Yeh, H. W. Huang, C. M. Yang, W. S. Yang, and C. H. Yang, "Astaxanthin inhibits expression of retinal oxidative stress and inflammatory mediators in streptozotocininduced diabetic rats," PLoS One, vol. 11, no. 1, article e0146438, 2016.

[74] K. Neelam, C. J. Goenadi, K. Lun, C. C. Yip, and K. G. Au Eong, "Putative protective role of lutein and zeaxanthin in diabetic retinopathy," British Journal of Ophthalmology, vol. 101, no. 5, pp. 551-558, 2017.

[75] X. Gong and L. P. Rubin, "Role of macular xanthophylls in prevention of common neovascular retinopathies: retinopathy of prematurity and diabetic retinopathy," Archives of Biochemistry and Biophysics, vol. 572, pp. 40-48, 2015.

[76] X. Zhou, F. Zhang, X. Hu et al., "Inhibition of inflammation by astaxanthin alleviates cognition deficits in diabetic mice," Physiology \& Behavior, vol. 151, pp. 412-420, 2015.

[77] B. Baccouche, M. Benlarbi, A. J. Barber, and R. Ben Chaouacha-Chekir, "Short-term administration of astaxanthin attenuates retinal changes in diet-induced DiabeticPsammomys obesus," Current Eye Research, vol. 43, no. 9, pp. 1177-1189, 2018.

[78] L. Y. Dong, J. Jin, G. Lu, and X. L. Kang, "Astaxanthin attenuates the apoptosis of retinal ganglion cells in $\mathrm{db} / \mathrm{db}$ mice by inhibition of oxidative stress," Marine Drugs, vol. 11, no. 12, pp. 960-974, 2013.

[79] S. Medjakovic and A. Jungbauer, "Pomegranate: a fruit that ameliorates metabolic syndrome," Food \& Function, vol. 4, no. 1, pp. 19-39, 2013.

[80] M. Konstantinidi and A. E. Koutelidakis, "Functional foods and bioactive compounds: a review of its possible role on weight management and obesity's metabolic consequences," Medicine, vol. 6, no. 3, p. 94, 2019.

[81] S. J. Padayatty and M. Levine, "Vitamin C: the known and the unknown and Goldilocks," Oral Diseases, vol. 22, no. 6, pp. 463-493, 2016.

[82] A. Braakhuis, R. Raman, and E. Vaghefi, "The association between dietary intake of antioxidants and ocular disease," Diseases, vol. 5, no. 1, p. 3, 2017.

[83] D. Kundu, T. Mandal, M. Nandi, M. Osta, U. Bandyopadhyay, and D. Ray, "Oxidative stress in diabetic patients with retinopathy," Annals of African Medicine, vol. 13, no. 1, p. 41, 2014.

[84] S. W. Park, W. Ghim, S. Oh et al., "Association of vitreous vitamin $C$ depletion with diabetic macular ischemia in proliferative diabetic retinopathy," PLoS One, vol. 14, no. 6, article e0218433, 2019.

[85] I. Young, "The effect of ascorbate supplementation on oxidative stress in the streptozotocin diabetic rat," Free Radical Biology and Medicine, vol. 13, no. 1, pp. 41-46, 1992. 
[86] M. M. Gupta and S. Chari, "Lipid peroxidation and antioxidant status in patients with diabetic retinopathy," Indian Journal of Physiology and Pharmacology, vol. 49, no. 2, pp. 187-192, 2005.

[87] J. Vinson, C. Hsu, C. Possanza et al., "Lipid peroxidation and diabetic complications: effect of antioxidant vitamins $\mathrm{C}$ and E," in Free Radicals in Diagnostic Medicine, D. Armstrong, Ed., vol. 366 of Advances in Experimental Medicine and Biology, pp. 430-432, Springer, Boston, MA USA, 1994.

[88] E. Ulker, W. H. Parker, A. Raj, Z. C. Qu, and J. M. May, "Ascorbic acid prevents VEGF-induced increases in endothelial barrier permeability," Molecular and Cellular Biochemistry, vol. 412, no. 1-2, pp. 73-79, 2016.

[89] A. Sorice, E. Guerriero, F. Capone, G. Colonna, G. Castello, and S. Costantini, "Ascorbic acid: its role in immune system and chronic inflammation diseases," Mini-Reviews in Medicinal Chemistry, vol. 14, no. 5, pp. 444-452, 2014.

[90] F. Kianian, S. M. Karimian, M. Kadkhodaee et al., "Combination of ascorbic acid and calcitriol attenuates chronic asthma disease by reductions in oxidative stress and inflammation," Respiratory Physiology \& Neurobiology, vol. 270, article 103265, 2019.

[91] T. Fujii, A. A. Udy, and B. Venkatesh, "Comparing apples and oranges: the vasoactive effects of hydrocortisone and studies investigating high dose vitamin $\mathrm{C}$ combination therapy in septic shock," Critical Care and Resuscitation, vol. 21, no. 3, pp. 152-155, 2019.

[92] H. Wang, Z. Zhang, R. Wen, and J. Chen, "Experimental and clinical studies on the reduction of erythrocyte sorbitolglucose ratios by ascorbic acid in diabetes mellitus," Diabetes Research and Clinical Practice, vol. 28, no. 1, pp. 1-8, 1995.

[93] J. M. May, A. Jayagopal, Z. C. Qu, and W. H. Parker, “Ascorbic acid prevents high glucose-induced apoptosis in human brain pericytes," Biochemical and Biophysical Research Communications, vol. 452, no. 1, pp. 112-117, 2014.

[94] M. Fukui, N. Yamabe, H.-J. Choi, K. Polireddy, Q. Chen, and B. Zhu, "Mechanism of ascorbate-induced cell death in human pancreatic cancer cells: role of Bcl-2, Beclin 1 and autophagy," Planta Medica, vol. 81, no. 10, pp. 838-846, 2015.

[95] A. Martin, J. A. Joseph, and A. M. Cuervo, "Stimulatory effect of vitamin C on autophagy in glial cells," Journal of Neurochemistry, vol. 82, no. 3, pp. 538-549, 2002.

[96] T. H. Hung, S. F. Chen, M. J. Li, Y. L. Yeh, and T.'. T.'. Hsieh, "Differential effects of concomitant use of vitamins $\mathrm{C}$ and $\mathrm{E}$ on trophoblast apoptosis and autophagy between normoxia and hypoxia-reoxygenation," PLoS One, vol. 5, no. 8, article e12202, 2010.

[97] X. Wang and P. J. Quinn, "Vitamin E and its function in membranes," Progress in Lipid Research, vol. 38, no. 4, pp. 309-336, 1999.

[98] S. K. Jain and M. Palmer, "The effect of oxygen radicals metabolites and vitamin E on glycosylation of proteins," Free Radical Biology and Medicine, vol. 22, no. 4, pp. 593-596, 1997.

[99] T.-W. Chung, J. J. Hau Yu, and D.-Z. Liu, "Reducing lipid peroxidation stress of erythrocyte membrane by $\alpha$-tocopherol nicotinate plays an important role in improving blood rheological properties in type 2 diabetic patients with retinopathy," Diabetic Medicine, vol. 15, no. 5, pp. 380-385, 1998.
[100] M. A. Haidara, H. Yassin, M. Rateb, H. Ammar, and M. Zorkani, "Role of oxidative stress in development of cardiovascular complications in diabetes mellitus," Current Vascular Pharmacology, vol. 4, no. 3, pp. 215-227, 2006.

[101] Y. Zhao, W. Zhang, Q. Jia et al., "High dose vitamin E attenuates diabetic nephropathy via alleviation of autophagic stress," Frontiers in Physiology, vol. 9, article 1939, 2019.

[102] T. Arablou, N. Aryaeian, M. Djalali, F. Shahram, and L. Rasouli, "Association between dietary intake of some antioxidant micronutrients with some inflammatory and antioxidant markers in active rheumatoid arthritis patients," International Journal for Vitamin and Nutrition Research, vol. 89, no. 5-6, pp. 238-245, 2019.

[103] A. Azzi, D. Boscoboinik, S. Clément et al., " $\alpha$-Tocopherol as a modulator of smooth muscle cell proliferation," Prostaglandins, Leukotrienes and Essential Fatty Acids, vol. 57, no. 4-5, pp. 507-514, 1997.

[104] M. Herbet, M. Izdebska, I. Piątkowska-Chmiel et al., " $\alpha$-Tocopherol ameliorates redox equilibrium and reduces inflammatory response caused by chronic variable stress," BioMed Research International, vol. 2018, Article ID 7210783, 12 pages, 2018.

[105] M. Kunisaki, S. E. Bursell, A. C. Clermont et al., "Vitamin E prevents diabetes-induced abnormal retinal blood flow via the diacylglycerol-protein kinase C pathway," American Journal of Physiology. Endocrinology and Metabolism, vol. 269, no. 2, pp. E239-E246, 1995.

[106] K. Nakagawa, A. Shibata, S. Yamashita et al., "In vivo angiogenesis is suppressed by unsaturated vitamin E, tocotrienol," The Journal of Nutrition, vol. 137, no. 8, pp. 1938-1943, 2007.

[107] M. Jarosz, M. Olbert, G. Wyszogrodzka, K. Młyniec, and T. Librowski, "Antioxidant and anti-inflammatory effects of zinc. Zinc-dependent NF- $\kappa$ B signaling," Inflammopharmacology, vol. 25, no. 1, pp. 11-24, 2017.

[108] X. Miao, W. Sun, L. Miao et al., "Zinc and diabetic retinopathy," Journal Diabetes Research, vol. 2013, article 425854, 8 pages, 2013.

[109] S. Kogan, A. Sood, and M. S. Garnick, "Zinc and wound healing: a review of zinc physiology and clinical applications," Wounds, vol. 29, no. 4, pp. 102-106, 2017.

[110] H. Dharamdasani Detaram, P. Mitchell, J. Russell, G. Burlutsky, G. Liew, and B. Gopinath, "Dietary zinc intake is associated with macular fluid in neovascular age-related macular degeneration," Clinical \& Experimental Ophthalmology, vol. 48, no. 1, pp. 61-68, 2019.

[111] H. Rostamkhani, A. A. Mellati, B. S. Tabaei, M. Alavi, and S. N. Mousavi, "Association of serum zinc and vitamin A levels with severity of retinopathy in type 2 diabetic patients: a cross-sectional study," Biological Trace Element Research, vol. 192, no. 2, pp. 123-128, 2019.

[112] Y. Y. Luo, J. Zhao, X. Y. Han, X. H. Zhou, J. Wu, and L. N. Ji, "Relationship between serum zinc level and microvascular complications in patients with type 2 diabetes," Chinese Medical Journal, vol. 128, no. 24, pp. 3276-3282, 2015.

[113] S. M. de Figueiredo Ribeiro, C. B. M. Braga, F. M. Peria et al., "Effect of zinc supplementation on antioxidant defenses and oxidative stress markers in patients undergoing chemotherapy for colorectal cancer: a placebo-controlled, prospective randomized trial," Biological Trace Element Research, vol. 169, no. 1, pp. 8-16, 2016. 
[114] C. H. Guo and C. L. Wang, "Effects of zinc supplementation on plasma copper/zinc ratios, oxidative stress, and immunological status in hemodialysis patients," International Journal of Medical Sciences, vol. 10, no. 1, pp. 79-89, 2013.

[115] P. Ranasinghe, S. Pigera, P. Galappatthy, P. Katulanda, and G. R. Constantine, "Zinc and diabetes mellitus: understanding molecular mechanisms and clinical implications," DARU Journal of Pharmaceutical Sciences, vol. 23, no. 1, p. 44, 2015.

[116] R. Sharif, P. Thomas, P. Zalewski, and M. Fenech, "Zinc supplementation influences genomic stability biomarkers, antioxidant activity, and zinc transporter genes in an elderly Australian population with low zinc status," Molecular Nutrition \& Food Research, vol. 59, no. 6, pp. 12001212, 2015.

[117] T. M. Bray and W. J. Bettger, "The physiological role of zinc as an antioxidant," Free Radical Biology and Medicine, vol. 8, no. 3, pp. 281-291, 1990.

[118] S. R. Lee, "Critical role of zinc as either an antioxidant or a prooxidant in cellular systems," Oxidative Medicine and Cellular Longevity, vol. 2018, Article ID 9156285, 11 pages, 2018.

[119] S. Barman and K. Srinivasan, "Attenuation of oxidative stress and cardioprotective effects of zinc supplementation in experimental diabetic rats," British Journal of Nutrition, vol. 117, no. 3, pp. 335-350, 2017.

[120] Z. Liu, X. Wu, T. Zhang et al., "Effects of dietary copper and zinc supplementation on growth performance, tissue mineral retention, antioxidant status, and fur quality in growingfurring blue foxes (Alopex lagopus)," Biological Trace Element Research, vol. 168, no. 2, pp. 401-410, 2015.

[121] S. Kheirouri, S. Naghizadeh, and M. Alizadeh, "Zinc supplementation does not influence serum levels of VEGF, BDNF, and NGF in diabetic retinopathy patients: a randomized controlled clinical trial," Nutritional Neuroscience, vol. 22, no. 10, pp. 718-724, 2019.

[122] J. Zhan, W. Qin, Y. Zhang et al., "Upregulation of neuronal zinc finger protein A20 expression is required for electroacupuncture to attenuate the cerebral inflammatory injury mediated by the nuclear factor- $\kappa \mathrm{B}$ signaling pathway in cerebral ischemia/reperfusion rats," Journal of Neuroinflammation, vol. 13, no. 1, p. 258, 2016.

[123] S. Fujimoto, H. Yasui, and Y. Yoshikawa, "Development of a novel antidiabetic zinc complex with an organoselenium ligand at the lowest dosage in KK- $\mathrm{A}^{\mathrm{y}}$ mice," Journal of Inorganic Biochemistry, vol. 121, pp. 10-15, 2013.

[124] S. Barman and K. Srinivasan, "Zinc supplementation ameliorates diabetic cataract through modulation of crystallin proteins and polyol pathway in experimental rats," Biological Trace Element Research, vol. 187, no. 1, pp. 212-223, 2019.

[125] T. V. Peres, M. R. C. Schettinger, P. Chen et al., "Manganeseinduced neurotoxicity: a review of its behavioral consequences and neuroprotective strategies," BMC Pharmacology and Toxicology, vol. 17, no. 1, p. 57, 2016.

[126] A. Sigel, H. Sigel, and R. K. O. Sigel, Eds., Interrelations between essential metal ions and human diseases, Metal Ions in Life Sciences, Springer Netherlands, 2013.

[127] B. Salmonowicz, M. Krzystek-Korpacka, and A. Noczyńska, "Trace elements, magnesium, and the efficacy of antioxidant systems in children with type 1 diabetes mellitus and in their siblings," Advances in Clinical and Experimental Medicine, vol. 23, no. 2, pp. 259-268, 2014.
[128] S. Du, X. Wu, T. Han et al., "Dietary manganese and type 2 diabetes mellitus: two prospective cohort studies in China," Diabetologia, vol. 61, no. 9, pp. 1985-1995, 2018.

[129] W.-D. Jiang, R. J. Tang, Y. Liu et al., "Impairment of gill structural integrity by manganese deficiency or excess related to induction of oxidative damage, apoptosis and dysfunction of the physical barrier as regulated by NF- $\kappa \mathrm{B}$, caspase and Nrf2 signaling in fish," Fish \& Shellfish Immunology, vol. 70, pp. 280-292, 2017.

[130] E. Burlet and S. K. Jain, "Manganese supplementation increases adiponectin and lowers ICAM-1 and creatinine blood levels in Zucker type 2 diabetic rats, and downregulates ICAM-1 by upregulating adiponectin multimerization protein (DsbA-L) in endothelial cells," Molecular and Cellular Biochemistry, vol. 429, no. 1-2, pp. 1-10, 2017.

[131] J. K. Kresovich, C. M. Bulka, B. T. Joyce et al., "The inflammatory potential of dietary manganese in a cohort of elderly men," Biological Trace Element Research, vol. 183, no. 1, pp. 49-57, 2018.

[132] J. D. Aguirre and V. C. Culotta, "Battles with iron: manganese in oxidative stress protection," Journal of Biological Chemistry, vol. 287, no. 17, pp. 13541-13548, 2012.

[133] E. J. Martinez-Finley, C. E. Gavin, M. Aschner, and T. E. Gunter, "Manganese neurotoxicity and the role of reactive oxygen species," Free Radical Biology and Medicine, vol. 62, pp. 65-75, 2013.

[134] S.-H. Lee, H. A. Jouihan, R. C. Cooksey et al., "Manganese supplementation protects against diet-induced diabetes in wild type mice by enhancing insulin secretion," Endocrinology, vol. 154, no. 3, pp. 1029-1038, 2013.

[135] M. B. Gomes and C. A. Negrato, "Alpha-lipoic acid as a pleiotropic compound with potential therapeutic use in diabetes and other chronic diseases," Diabetology \& Metabolic Syndrome, vol. 6, no. 1, 2014.

[136] Y. S. Kim, M. Kim, M. Y. Choi et al., "Alpha-lipoic acid reduces retinal cell death in diabetic mice," Biochemical and Biophysical Research Communications, vol. 503, no. 3, pp. 1307-1314, 2018.

[137] L. Packer, "Antioxidant properties of lipoic acid and its therapeutic effects in prevention of diabetes complications and cataractsa," Annals of the New York Academy of Sciences, vol. 738, no. 1, pp. 257-264, 1994.

[138] J. H. Suh, S. V. Shenvi, B. M. Dixon et al., "Decline in transcriptional activity of Nrf2 causes age-related loss of glutathione synthesis, which is reversible with lipoic acid," Proceedings of the National Academy of Sciences of the United States of America, vol. 101, no. 10, pp. 3381-3386, 2004.

[139] G. P. Biewenga, G. R. M. M. Haenen, and A. Bast, "The pharmacology of the antioxidant lipoic acid," General Pharmacology: The Vascular System, vol. 29, no. 3, pp. 315-331, 1997.

[140] M. Dworacka, G. Chukanova, S. Iskakova et al., "New arguments for beneficial effects of alpha-lipoic acid on the cardiovascular system in the course of type 2 diabetes," European Journal of Pharmaceutical Sciences, vol. 117, pp. 41-47, 2018.

[141] S. G. Lee, C. G. Lee, I. H. Yun, D. Y. Hur, J. W. Yang, and H. W. Kim, "Effect of lipoic acid on expression of angiogenic factors in diabetic rat retina," Clinical \& Experimental Ophthalmology, vol. 40, no. 1, pp. e47-e57, 2012.

[142] E. Kan, Ö. Alici, E. K. Kan, and A. Ayar, "Effects of alphalipoic acid on retinal ganglion cells, retinal thicknesses, and VEGF production in an experimental model of diabetes," 
International Ophthalmology, vol. 37, no. 6, pp. 1269-1278, 2017.

[143] M. Artwohl, K. Muth, K. Kosulin et al., "R-(+)- $\alpha$-lipoic acid inhibits endothelial cell apoptosis and proliferation: involvement of Akt and retinoblastoma protein/E2F-1," American Journal of Physiology. Endocrinology and Metabolism, vol. 293, no. 3, pp. E681-E689, 2007.

[144] C.-L. Chen, W. S. Cheng, J. L. Chen, and C. H. Chiang, "Potential of nonoral $\alpha$-lipoic acid aqueous formulations to reduce ocular microvascular complications in a streptozotocin-induced diabetic rat model," Journal of Ocular Pharmacology and Therapeutics, vol. 29, no. 8, pp. 738-745, 2013.

[145] J. M. Santos and R. A. Kowluru, "Role of mitochondria biogenesis in the metabolic memory associated with the continued progression of diabetic retinopathy and its regulation by lipoic acid," Investigative Opthalmology \& Visual Science, vol. 52, no. 12, pp. 8791-8798, 2011.

[146] M. Nebbioso, F. Pranno, and N. Pescosolido, "Lipoic acid in animal models and clinical use in diabetic retinopathy," Expert Opinion on Pharmacotherapy, vol. 14, no. 13, pp. 1829-1838, 2013.

[147] J. Lin, A. Bierhaus, P. Bugert et al., "Effect of R-(+)- $\alpha$-lipoic acid on experimental diabetic retinopathy," Diabetologia, vol. 49, no. 5, pp. 1089-1096, 2006.

[148] M. Nebbioso, M. Federici, D. Rusciano, M. Evangelista, and N. Pescosolido, "Oxidative stress in preretinopathic diabetes subjects and antioxidants," Diabetes Technology \& Therapeutics, vol. 14, no. 3, pp. 257-263, 2012.

[149] C. Haritoglou, J. Gerss, H. P. Hammes, A. Kampik, M. W. Ulbig, and RETIPON Study Group, "Alpha-lipoic acid for the prevention of diabetic macular edema," Ophthalmologica, vol. 226, no. 3, pp. 127-137, 2011.

[150] T. Tsuda, "Curcumin as a functional food-derived factor: degradation products, metabolites, bioactivity, and future perspectives," Food \& Function, vol. 9, no. 2, pp. 705-714, 2018.

[151] M. L. A. D. Lestari and G. Indrayanto, "Curcumin," in Profiles of Drug Substances, Excipients and Related Methodology, pp. 113-204, 2014.

[152] World Health Organization and Food and Agriculture Organization of the United Nations \& Joint FAO/WHO Expert Committee on Food Additives. Meeting (80th: 2015, Rome, Italy), "Evaluation of Certain Food Additives and Contaminants: Eightieth Report of the Joint FAO/WHO Expert Committee on Food Additives," World Health Organization, 2016, https://apps.who.int/iris/ handle/10665/204410.

[153] D. M. Radomska-Leśniewska, A. Osiecka-Iwan, A. Hyc, A. Góźdź, A. M. Dąbrowska, and P. Skopiński, "Therapeutic potential of curcumin in eye diseases," CentralEuropean Journal of Immunology, vol. 44, no. 2, pp. 181-189, 2019.

[154] K. M. Nelson, J. L. Dahlin, J. Bisson, J. Graham, G. F. Pauli, and M. A. Walters, "The essential medicinal chemistry of curcumin," Journal of Medicinal Chemistry, vol. 60, no. 5, pp. 1620-1637, 2017.

[155] N. Parsamanesh, M. Moossavi, A. Bahrami, A. E. Butler, and A. Sahebkar, "Therapeutic potential of curcumin in diabetic complications," Pharmacological Research, vol. 136, pp. 181-193, 2018.
[156] S. Pinlaor, P. Yongvanit, S. Prakobwong et al., "Curcumin reduces oxidative and nitrative DNA damage through balancing of oxidant-antioxidant status in hamsters infected with Opisthorchis viverrini," Molecular Nutrition \& Food Research, vol. 53, no. 10, pp. 1316-1328, 2009.

[157] S. Kadam, M. Kanitkar, K. Dixit, R. Deshpande, V. Seshadri, and V. Kale, "Curcumin reverses diabetes-induced endothelial progenitor cell dysfunction by enhancing MnSOD expression and activity in vitro and in vivo," Journal of Tissue Engineering and Regenerative Medicine, vol. 12, no. 7, pp. 1594-1607, 2018.

[158] K. V. Peddada, A.'. Brown, V. Verma, and M. Nebbioso, "Therapeutic potential of curcumin in major retinal pathologies," International Ophthalmology, vol. 39, no. 3, pp. 725734, 2019.

[159] Z. Ran, Y. Zhang, X. Wen, and J. Ma, "Curcumin inhibits high glucose-induced inflammatory injury in human retinal pigment epithelial cells through the ROS-PI3K/AKT/mTOR signaling pathway," Molecular Medicine Reports, vol. 19, no. 2, pp. 1024-1031, 2019.

[160] Z. Sameermahmood, M. Balasubramanyam, T. Saravanan, and M. Rema, "Curcumin modulates SDF-1 $\alpha /$ CXCR4induced migration of human retinal endothelial cells (HRECs)," Investigative Opthalmology \& Visual Science, vol. 49 , no. 8 , article 3305, 2008.

[161] S. Nakamura, T. Noguchi, Y. Inoue et al., "Nrf2 activator RS9 suppresses pathological ocular angiogenesis and hyperpermeability," Investigative Opthalmology \& Visual Science, vol. 60, no. 6, p. 1943, 2019.

[162] S. Nabavi, R. Thiagarajan, L. Rastrelli et al., "Curcumin: a natural product for diabetes and its complications," Current Topics in Medicinal Chemistry, vol. 15, no. 23, pp. 2445$2455,2015$.

[163] L.-L. Wang, Y. Sun, K. Huang, and L. Zheng, "Curcumin, a potential therapeutic candidate for retinal diseases," Molecular Nutrition \& Food Research, vol. 57, no. 9, pp. 1557-1568, 2013.

[164] I. Krga and D. Milenkovic, "Anthocyanins: from sources and bioavailability to cardiovascular health benefits and molecular mechanisms of action," Journal of Agricultural and Food Chemistry, vol. 67, no. 7, pp. 1771-1783, 2019.

[165] M. A. Lila, B. Burton-Freeman, M. Grace, and W. Kalt, "Unraveling anthocyanin bioavailability for human health," Annual Review of Food Science and Technology, vol. 7, no. 1, pp. 375-393, 2016.

[166] Y. M. Lee, Y. Yoon, H. Yoon, H. M. Park, S. Song, and K. J. Yeum, "Dietary anthocyanins against obesity and inflammation," Nutrients, vol. 9, no. 10, article 1089, 2017.

[167] J. Fang, "Bioavailability of anthocyanins," Drug Metabolism Reviews, vol. 46, no. 4, pp. 508-520, 2014.

[168] D. Li, P. Wang, Y. Luo, M. Zhao, and F. Chen, "Health benefits of anthocyanins and molecular mechanisms: update from recent decade," Critical Reviews in Food Science and Nutrition, vol. 57, no. 8, pp. 1729-1741, 2015.

[169] D. Różańska and B. Regulska-Ilow, "The significance of anthocyanins in the prevention and treatment of type 2 diabetes," Advances in Clinical and Experimental Medicine, vol. 27, no. 1, pp. 135-142, 2018.

[170] S. Bungau, M. M. Abdel-Daim, D. M. Tit et al., "Health benefits of polyphenols and carotenoids in age-related eye 
diseases," Oxidative Medicine and Cellular Longevity, vol. 2019, Article ID 9783429, 22 pages, 2019.

[171] W. Huang, Z. Yan, D. Li, Y. Ma, J. Zhou, and Z. Sui, “Antioxidant and anti-inflammatory effects of blueberry anthocyanins on high glucose-induced human retinal capillary endothelial cells," Oxidative Medicine and Cellular Longevity, vol. 2018, Article ID 1862462, 10 pages, 2018.

[172] H. Wang, M. G. Nair, G. M. Strasburg et al., "Antioxidant and antiinflammatory activities of anthocyanins and their aglycon, cyanidin, from tart cherries," Journal of Natural Products, vol. 62, no. 2, pp. 294-296, 1999.

[173] A. Aboonabi and I. Singh, "Chemopreventive role of anthocyanins in atherosclerosis via activation of Nrf2-ARE as an indicator and modulator of redox," Biomedicine \& Pharmacotherapy, vol. 72, pp. 30-36, 2015.

[174] B. Salehi, A. Mishra, M. Nigam et al., "Resveratrol: a doubleedged sword in health benefits," Biomedicine, vol. 6, no. 3, p. 91, 2018.

[175] J. Li, S. Yu, J. Ying, T. Shi, and P. Wang, "Resveratrol prevents ROS-induced apoptosis in high glucose-treated retinal capillary endothelial cells via the activation of AMPK/Sirt1/PGC$1 \alpha$ pathway," Oxidative Medicine and Cellular Longevity, vol. 2017, Article ID 7584691, 10 pages, 2017.

[176] M. D. Toro, K. Nowomiejska, T. Avitabile et al., "Effect of resveratrol on in vitro and in vivo models of diabetic retinophathy: a systematic review," International Journal of Molecular Sciences, vol. 20, no. 14, article 3503, 2019.

[177] Y. Chen, J. Meng, H. Li et al., "Resveratrol exhibits an effect on attenuating retina inflammatory condition and damage of diabetic retinopathy via PON1," Experimental Eye Research, vol. 181, pp. 356-366, 2019.

[178] M. Popescu, C. Bogdan, A. Pintea, D. Rugină, and C. Ionescu, "Antiangiogenic cytokines as potential new therapeutic targets for resveratrol in diabetic retinopathy," Drug Design, Development and Therapy, vol. 12, pp. 19851996, 2018.

[179] K. Zeng, Y. Wang, N. Yang et al., "Resveratrol inhibits diabetic-induced Müller cells apoptosis through microRNA29b/specificity protein 1 pathway," Molecular Neurobiology, vol. 54, no. 6, pp. 4000-4014, 2017.

[180] H. Seong, J. Ryu, W. S. Yoo et al., "Resveratrol ameliorates retinal ischemia/reperfusion injury in C57BL/6J mice via downregulation of caspase-3," Current Eye Research, vol. 42, no. 12, pp. 1650-1658, 2017.

[181] H. Guo and W. Ling, "The update of anthocyanins on obesity and type 2 diabetes: experimental evidence and clinical perspectives," Reviews in Endocrine \& Metabolic Disorders, vol. 16, no. 1, pp. 1-13, 2015.

[182] Y. Wang and S. Hekimi, "Understanding ubiquinone," Trends in Cell Biology, vol. 26, no. 5, pp. 367-378, 2016.

[183] K. Žmitek, T. Pogačnik, L. Mervic, J. Žmitek, and I. Pravst, "The effect of dietary intake of coenzyme Q10 on skin parameters and condition: results of a randomised, placebocontrolled, double-blind study," BioFactors, vol. 43, no. 1, pp. 132-140, 2017.

[184] J. Garrido-Maraver, "Clinical applications of coenzyme $\mathrm{Q}_{10}$ ”" Frontiers in Bioscience, vol. 19, no. 4, p. 619, 2014.

[185] S. C. Lim, H. H. Tan, S. K. Goh et al., "Oxidative burden in prediabetic and diabetic individuals: evidence from plasma coenzyme Q10," Diabetic Medicine, vol. 23, no. 12, pp. 1344-1349, 2006.
[186] J. Lopez-Moreno, G. M. Quintana-Navarro, J. Delgado-Lista et al., "Mediterranean diet supplemented with coenzyme $\mathrm{Q}_{10}$ Modulates the postprandial metabolism of advanced glycation end products in elderly men and women," The Journals of Gerontology Series A: Biological Sciences and Medical Sciences, vol. 73, no. 3, pp. 340-346, 2016.

[187] C. H. Yen, Y. J. Chu, B. J. Lee, Y. C. Lin, and P. T. Lin, “Effect of liquid ubiquinol supplementation on glucose, lipids and antioxidant capacity in type 2 diabetes patients: a doubleblind, randomised, placebo-controlled trial," British Journal of Nutrition, vol. 120, no. 1, pp. 57-63, 2018.

[188] T. Gholnari, E. Aghadavod, A. Soleimani, G. A. Hamidi, N. Sharifi, and Z. Asemi, "The effects of coenzyme Q10 supplementation on glucose metabolism, lipid profiles, inflammation, and oxidative stress in patients with diabetic nephropathy: a randomized, double-blind, placebocontrolled trial," Journal of the American College of Nutrition, vol. 37, no. 3, pp. 188-193, 2017.

[189] A. D. Rodríguez-Carrizalez, J. A. Castellanos-González, E. C. Martínez-Romero et al., "The effect of ubiquinone and combined antioxidant therapy on oxidative stress markers in non-proliferative diabetic retinopathy: a phase IIa, randomized, double-blind, and placebo-controlled study," Redox Report, vol. 21, no. 4, pp. 155-163, 2015.

[190] X. Zhang, A. M. Tohari, F. Marcheggiani et al., "Therapeutic potential of co-enzyme Q10 in retinal diseases," Current Medicinal Chemistry, vol. 24, no. 39, pp. 4329-4339, 2017.

[191] T. Behl and A. Kotwani, "Omega-3 fatty acids in prevention of diabetic retinopathy," Journal of Pharmacy and Pharmacology, vol. 69, no. 8, pp. 946-954, 2017.

[192] Y. Gong, Z. Fu, R. Liegl, J. Chen, A. Hellström, and L. E. Smith, " $\omega-3$ and $\omega-6$ long-chain PUFAs and their enzymatic metabolites in neovascular eye diseases," The American Journal of Clinical Nutrition, vol. 106, no. 1, pp. 16-26, 2017.

[193] K. M. Connor, J. P. SanGiovanni, C. Lofqvist et al., "Increased dietary intake of omega-3-polyunsaturated fatty acids reduces pathological retinal angiogenesis," Nature Medicine, vol. 13, no. 7, pp. 868-873, 2007.

[194] M. N. Dátilo, M. R. Sant'Ana, G. P. Formigari et al., “Omega3 from flaxseed oil protects obese mice against diabetic retinopathy through GPR120 receptor," Scientific Reports, vol. 8, no. 1, article 14318, 2018.

[195] M. Lepretti, S. Martucciello, M. Burgos Aceves, R. Putti, and L. Lionetti, "Omega-3 fatty acids and insulin resistance: focus on the regulation of mitochondria and endoplasmic reticulum stress," Nutrients, vol. 10, no. 3, p. 350, 2018.

[196] A. Sala-Vila, A. Díaz-López, C. Valls-Pedret et al., "Dietary marine $\omega$-3 fatty acids and incident sight-threatening retinopathy in middle-aged and older individuals with type 2 diabetes," JAMA Ophthalmology, vol. 134, no. 10, pp. 11421149, 2016.

[197] Z. Yu, C. Gong, B. Lu et al., "Dendrobium chrysotoxum Lindl. alleviates diabetic retinopathy by preventing retinal inflammation and tight junction protein decrease," Journal Diabetes Research, vol. 2015, article 518317, 10 pages, 2015.

[198] Y.-Q. Gong, Y. Fan, D.-Z. Wu, H. Yang, Z.-B. Hu, and Z.-T. Wang, "In vivo and in vitro evaluation of erianin, a novel anti-angiogenic agent," European Journal of Cancer, vol. 40, no. 10, pp. 1554-1565, 2004.

[199] T. Zhang, H. Ouyang, X. Mei et al., "Erianin alleviates diabetic retinopathy by reducing retinal inflammation initiated by microglial cellsviainhibiting hyperglycemia-mediated 
ERK1/2-NF- $\kappa$ B signaling pathway," The FASEB Journal, vol. 33, no. 11, pp. 11776-11790, 2019.

[200] F. G. do Amaral and J. Cipolla-Neto, "A brief review about melatonin, a pineal hormone," Archives of Endocrinology and Metabolism, vol. 62, no. 4, pp. 472-479, 2018.

[201] H. S. Tuli, D. Kashyap, A. K. Sharma, and S. S. Sandhu, "Molecular aspects of melatonin (MLT)-mediated therapeutic effects," Life Sciences, vol. 135, pp. 147-157, 2015.

[202] E. Dehdashtian, S. Mehrzadi, B. Yousefi et al., "Diabetic retinopathy pathogenesis and the ameliorating effects of melatonin; involvement of autophagy, inflammation and oxidative stress," Life Sciences, vol. 193, pp. 20-33, 2018.

[203] B. Djordjevic, T. Cvetkovic, T. J. Stoimenov et al., "Oral supplementation with melatonin reduces oxidative damage and concentrations of inducible nitric oxide synthase, VEGF and matrix metalloproteinase 9 in the retina of rats with streptozotocin/nicotinamide induced pre-diabetes," European Journal of Pharmacology, vol. 833, pp. 290-297, 2018.

[204] C. del Valle Bessone, H. D. Fajreldines, G. E. D. de Barboza et al., "Protective role of melatonin on retinal ganglionar cell: in vitro an in vivo evidences," Life Sciences, vol. 218, pp. 233240, 2019.

[205] S. Ba-Ali, A. E. Brøndsted, H. U. Andersen, B. Sander, P. J. Jennum, and H. Lund-Andersen, "Assessment of diurnal melatonin, cortisol, activity, and sleep-wake cycle in patients with and without diabetic retinopathy," Sleep Medicine, vol. 54, pp. 35-42, 2018.

[206] S. A. Hussain, H. M. Khadim, B. H. Khalaf, S. H. Ismail, K. I. Hussein, and A. S. Sahib, "Effects of melatonin and zinc on glycemic control in type 2 diabetic patients poorly controlled with metformin," Saudi Medical Journal, vol. 27, no. 10, pp. 1483-1488, 2006.

[207] C. Bucolo, G. Marrazzo, C. B. M. Platania, F. Drago, G. M. Leggio, and S. Salomone, "Fortified extract of red berry, Ginkgo biloba, and white willow bark in experimental early diabetic retinopathy," Journal Diabetes Research, vol. 2013, article 432695, 6 pages, 2013.

[208] D. Jin, J. Tian, Q. Bao et al., "Does adjuvant treatment with Chinese herbal medicine to antidiabetic agents have additional benefits in patients with type 2 diabetes? A system review and meta-analysis of randomized controlled trials," Evidence-based Complementary and Alternative Medicine, vol. 2019, Article ID 1825750, 14 pages, 2019.

[209] O. Tabatabaei-Malazy, E. Ardeshirlarijani, N. Namazi, S. Nikfar, R. B. Jalili, and B. Larijani, "Dietary antioxidative supplements and diabetic retinopathy; a systematic review," Journal of Diabetes \& Metabolic Disorders, vol. 18, no. 2, pp. 705-716, 2019.

[210] M. S. Farvid, F. Homayouni, Z. Amiri, and F. Adelmanesh, "Improving neuropathy scores in type 2 diabetic patients using micronutrients supplementation," Diabetes Research and Clinical Practice, vol. 93, no. 1, pp. 86-94, 2011.

[211] L. M. Title, P. M. Cummings, K. Giddens, and B. A. Nassar, "Oral glucose loading acutely attenuates endotheliumdependent vasodilation in healthy adults without diabetes: an effect prevented by vitamins C and E," Journal of the American College of Cardiology, vol. 36, no. 7, pp. 21852191, 2000

[212] B. Narotzki, A. Z. Reznick, D. Navot-Mintzer, B. Dagan, and Y. Levy, "Green tea and vitamin E enhance exercise-induced benefits in body composition, glucose homeostasis, and antioxidant status in elderly men and women," Journal of the
American College of Nutrition, vol. 32, no. 1, pp. 31-40, 2013.

[213] D. R. Galasko, E. Peskind, C. M. Clark et al., "Antioxidants for Alzheimer disease: a randomized clinical trial with cerebrospinal fluid biomarker measures," Archives of Neurology, vol. 69, no. 7, pp. 836-841, 2012.

[214] J. F. Polanski and O. L. Cruz, "Evaluation of antioxidant treatment in presbyacusis: prospective, placebo-controlled, double-blind, randomised trial," The Journal of Laryngology \& Otology, vol. 127, no. 2, pp. 134-141, 2013.

[215] A. D. Rodríguez-Carrizalez, J. A. Castellanos-González, E. C. Martínez-Romero et al., "The antioxidant effect of ubiquinone and combined therapy on mitochondrial function in blood cells in non-proliferative diabetic retinopathy: a randomized, double-blind, phase IIa, placebo-controlled study," Redox Report, vol. 21, no. 4, pp. 190-195, 2016.

[216] M. Lafuente, L. Ortín, M. Argente et al., "Three-year outcomes in a randomized single-blind controlled trial of intravitreal ranibizumab and oral supplementation with docosahexaenoic acid and antioxidants for diabetic macular edema," Retina, vol. 39, no. 6, pp. 1083-1090, 2019.

[217] R. A. Kowluru, Q. Zhong, J. M. Santos, M. Thandampallayam, D. Putt, and D. L. Gierhart, "Beneficial effects of the nutritional supplements on the development of diabetic retinopathy," Nutrition and Metabolism, vol. 11, no. 1, p. 8, 2014.

[218] T. K. Motawi, H. A. Darwish, M. A. Hamed, N. S. El-Rigal, and A. F. A. Naser, "A therapeutic Insight of niacin and coenzyme Q10 against diabetic encephalopathy in rats," Molecular Neurobiology, vol. 54, no. 3, pp. 1601-1611, 2017.

[219] J. Wattanathorn, P. Thiraphatthanavong, W. Thukham-Mee, S. Muchimapura, P. Wannanond, and T. Tong-Un, "Anticataractogenesis and Antiretinopathy Effects of the Novel Protective Agent Containing the Combined Extract of Mango and Vietnamese Coriander in STZ-Diabetic Rats," Oxidative Medicine and Cellular Longevity, vol. 2017, Article ID 5290161, 13 pages, 2017.

[220] T. Ahmed, S. R. Archie, A. Faruk, F. A. Chowdhury, A. Al Shoyaib, and C. R. Ahsan, "Evaluation of the antiinflammatory activities of diclofenac sodium, prednisolone and atorvastatin in combination with ascorbic acid," AntiInflammatory \& Anti-Allergy Agents in Medicinal Chemistry, vol. 18, 2019.

[221] A. J. T. Yang, S. Frendo-Cumbo, and R. E. K. MacPherson, "Resveratrol and metformin recover prefrontal cortex AMPK activation in diet-induced obese mice but reduce BDNF and synaptophysin protein content," Journal of Alzheimer's Disease, vol. 71, no. 3, pp. 945-956, 2019.

[222] A. Gurreri, A. Pazzaglia, and C. Schiavi, "Role of statins and ascorbic acid in the natural history of diabetic retinopathy: a new, affordable therapy?," Ophthalmic Surgery, Lasers \& Imaging Retina, vol. 50, no. 5, pp. S23-S27, 2019.

[223] Y. Wang, J. Tao, and Y. Yao, "Prostaglandin E2 Activates NLRP3 inflammasome in endothelial cells to promote diabetic retinopathy," Hormone and Metabolic Research, vol. 50, no. 9, pp. 704-710, 2018.

[224] F. Semeraro, A. Russo, E. Gambicorti et al., "Efficacy and vitreous levels of topical NSAIDs," Expert Opinion on Drug Delivery, vol. 12, no. 11, pp. 1767-1782, 2015.

[225] A. Russo, F. Morescalchi, S. Vezzoli et al., "Reduction of vitreous prostaglandin $\mathrm{E} 2$ levels after topical administration of 
indomethacin $0.5 \%$, bromfenac $0.09 \%$, and nepafenac $0.1 \%$., Retina, vol. 36, no. 6, pp. 1227-1231, 2016.

[226] S. M. Friedman, T. H. Almukhtar, C. W. Baker et al., "Topical nepafenec in eyes with noncentral diabetic macular edema," Retina, vol. 35, no. 5, pp. 944-956, 2015.

[227] F. Evliyaoğlu, Ç. Akpolat, M. M. Kurt, O. Çekiç, and M. Nuri Elçioğlu, "Retinal vascular caliber changes after topical nepafenac treatment for diabetic macular edema," Current Eye Research, vol. 43, no. 3, pp. 357-361, 2017.

[228] A. Grzybowski and J. Adamiec-Mroczek, "Topical nonsteroidal anti-inflammatory drugs for cystoid macular edema prevention in patients with diabetic retinopathy," American Journal of Ophthalmology, vol. 181, pp. xivxvi, 2017.

[229] H. Tang, G. Li, Y. Zhao et al., "Comparisons of diabetic retinopathy events associated with glucose-lowering drugs in patients with type 2 diabetes mellitus: a network meta-analysis," Diabetes, Obesity and Metabolism, vol. 20, no. 5, pp. 1262-1279, 2018.

[230] E. Y.-C. Kang, T. H. Chen, S. J. Garg et al., “Association of statin therapy with prevention of vision-threatening diabetic retinopathy," JAMA Ophthalmology, vol. 137, no. 4, pp. 363-371, 2019.

[231] D. Vail, N. F. Callaway, C. A. Ludwig, N. Saroj, and D. M. Moshfeghi, "Lipid-Lowering Medications Are Associated with Lower Risk of Retinopathy and Ophthalmic Interventions among United States Patients with Diabetes," American Journal of Ophthalmology, vol. 207, pp. 378-384, 2019.

[232] J. L. Wilkinson-Berka, V. Suphapimol, J. R. Jerome, D. Deliyanti, and M. J. Allingham, "Angiotensin II and aldosterone in retinal vasculopathy and inflammation," Experimental Eye Research, vol. 187, article 107766, 2019.

[233] J. A. Phipps, M. A. Dixon, A. I. Jobling et al., "The reninangiotensin system and the retinal neurovascular unit: a role in vascular regulation and disease," Experimental Eye Research, vol. 187, article 107753, 2019.

[234] B. Wang, F. Wang, Y. Zhang et al., "Effects of RAS inhibitors on diabetic retinopathy: a systematic review and meta-analysis," The Lancet Diabetes \& Endocrinology, vol. 3, no. 4, pp. 263-274, 2015.

[235] Q. Liu, F. Zhang, X. Zhang et al., "Fenofibrate ameliorates diabetic retinopathy by modulating Nrf2 signaling and NLRP3 inflammasome activation," Molecular and Cellular Biochemistry, vol. 445, no. 1-2, pp. 105-115, 2018.

[236] C. L. Morgan, D. R. Owens, P. Aubonnet et al., "Primary prevention of diabetic retinopathy with fibrates: a retrospective, matched cohort study," BMJ Open, vol. 3, no. 12, article e004025, 2013.

[237] R. Shi, L. Zhao, and Y. Qi, “The effect of fenofibrate on early retinal nerve fiber layer loss in type 2 diabetic patients: a casecontrol study," BMC Ophthalmology, vol. 18, no. 1, p. 100, 2018.

[238] S. Stewart and N. Lois, "Fenofibrate for diabetic retinopathy," Asia-Pacific Journal of Ophthalmology, vol. 7, no. 6, pp. 422426, 2019.

[239] J. E. Knickelbein, A. B. Abbott, and E. Y. Chew, "Fenofibrate and diabetic retinopathy," Current Diabetes Reports, vol. 16, no. 10, p. 90, 2016.

[240] X. J. Su, L. Han, Y. X. Qi, and H. W. Liu, "Efficacy of fenofibrate for diabetic retinopathy: a systematic review protocol," Medicine, vol. 98, no. 14, article e14999, 2019.
[241] A. R. Santos, L. Ribeiro, F. Bandello et al., "Functional and structural findings of neurodegeneration in early stages of diabetic retinopathy: cross-sectional analyses of baseline data of the EUROCONDOR Project," Diabetes, vol. 66, no. 9, pp. 2503-2510, 2017.

[242] O. Simó-Servat, C. Hernández, and R. Simó, "Somatostatin and diabetic retinopathy: an evolving story," Endocrine, vol. 60, no. 1, pp. 1-3, 2018.

[243] US Food and Drug Administration, "D ALPHAGAN ${ }^{\circledR}$ (brimonidine tartrate ophthalmic solution)," 2016, https://www .accessdata.fda.gov/drugsatfda_docs/label/2016/ 020613s031lbl.pdf.

[244] P. C. Gupta, S. Sood, S. Narang, and P. Ichhpujani, "Role of brimonidine in the treatment of clinically significant macular edema with ischemic changes in diabetic maculopathy," International Ophthalmology, vol. 34, no. 4, pp. 787-792, 2014.

[245] J. Grauslund, U. Frydkjaer-Olsen, T. Peto et al., "Topical treatment with brimonidine and somatostatin causes retinal vascular dilation in patients with early diabetic retinopathy from the EUROCONDOR," Investigative Opthalmology \& Visual Science, vol. 60, no. 6, p. 2257, 2019.

[246] R. Simó, C. Hernández, M. Porta et al., "Effects of topically administered neuroprotective drugs in early stages of diabetic retinopathy: Results of the EUROCONDOR Clinical Trial," Diabetes, vol. 68, no. 2, pp. 457-463, 2019.

[247] A. Honasoge, E. Nudleman, M. Smith, and R. Rajagopal, "Emerging insights and interventions for diabetic retinopathy," Current Diabetes Reports, vol. 19, no. 10, p. 100, 2019.

[248] K. Nayak and M. Misra, "A review on recent drug delivery systems for posterior segment of eye," Biomedicine \& Pharmacotherapy, vol. 107, pp. 1564-1582, 2018.

[249] A. Das, P. G. McGuire, and F. Monickaraj, "Novel pharmacotherapies in diabetic retinopathy: current status and what's in the horizon?," Indian Journal of Ophthalmology, vol. 64, no. 1, pp. 4-13, 2016.

[250] S. Jiang, Y. L. Franco, Y. Zhou, and J. Chen, "Nanotechnology in retinal drug delivery," International Journal of Ophthalmology, vol. 11, no. 6, pp. 1038-1044, 2018.

[251] M. Whitehead, A. Osborne, P. S. Widdowson, P. Yu-WaiMan, and K. R. Martin, "Angiopoietins in diabetic retinopathy: current understanding and therapeutic potential," Journal Diabetes Research, vol. 2019, article 5140521, 9 pages, 2019.

[252] M. T. Bolinger and D. A. Antonetti, "Moving past antiVEGF: novel therapies for treating diabetic retinopathy," International Journal of Molecular Sciences, vol. 17, no. 9, p. $1498,2016$.

[253] M. Campbell and S. L. Doyle, "Current perspectives on established and novel therapies for pathological neovascularization in retinal disease," Biochemical Pharmacology, vol. 164, pp. 321-325, 2019.

[254] Y. Dong, G. Wan, P. Yan, C. Qian, F. Li, and G. Peng, "Fabrication of resveratrol coated gold nanoparticles and investigation of their effect on diabetic retinopathy in streptozotocin induced diabetic rats," Journal of Photochemistry and Photobiology B: Biology, vol. 195, pp. 51-57, 2019.

[255] K. A. Elbana, H. M. Salem, N. R. Abdel Fattah, and E. Etman, "Serum pentraxin 3 level as a recent biomarker of diabetic retinopathy in Egyptian patients with diabetes," Diabetes and Metabolic Syndrome: Clinical Research and Reviews, vol. 13, no. 4, pp. 2361-2364, 2019. 